\title{
ARTICLE \\ WX20120108, a novel IAP antagonist, induces tumor cell autophagy via activating ROS-FOXO pathway
}

\author{
Rui Ding ${ }^{1,2}$, Xin Wang ${ }^{1}$, Wei Chen ${ }^{1}$, Zhi Li ${ }^{1}$, Ai-li Wei', Qing-bin Wang ${ }^{1}$, Ai-hua Nie ${ }^{1}$ and Li-li Wang ${ }^{1,2}$
}

\begin{abstract}
Recently, inhibitor of apoptosis proteins (IAPs) and some IAP antagonists were found to regulate autophagy, but the underlying mechanisms remain unclear. WX20120108 is an analogue of GDC-0152 (a known IAP antagonist) and displays more potent antitumor and autophagy-regulating activity in tumor cells, we investigated the regulatory mechanisms underlying WX20120108induced autophagy. Using molecular docking and fluorescence polarization anisotropy (FPA) competitive assay, we first demonstrated that WX20120108, acting as an IAP antagonist, bound to the XIAP-BIR3, XIAP BIR2-BIR3, CIAP1 BIR3, and CIAP2 BIR3 domains with high affinities. In six cancer cell lines, WX20120108 inhibited the cell proliferation with potencies two to ten-fold higher than that of GDC-0152. In HeLa and MDA-MB-231 cells, WX20120108 induced caspase-dependent apoptosis and activated TNFa-dependent extrinsic apoptosis. On the other hand, WX20120108 induced autophagy in HeLa and MDA-MB-231 cells in doseand time-dependent manners. We revealed that WX20120108 selectively activated Foxo3, evidenced by Foxo3 nuclear translocation in both gene modified cell line and HeLa cells, as well as the upregulated expression of Foxo3-targeted genes (Bnip3, Pik3c3, Atg5, and Atg4b), which played a key role in autophagy initiation. WX20120108-induced autophagy was significantly suppressed when Foxo3 gene was silenced. WX20120108 dose-dependently increased the generation of reactive oxygen species (ROS) in HeLa cells, and WX20120108-induced Foxo3 activation was completely blocked in the presence of catalase, a known ROS scavenger. However, WX20120108-induced ROS generation was not affected by CIAP1/2 or XIAP gene silencing. In conclusion, WX20120108-induced autophagy relies on activating ROS-Foxo3 pathway, which is independent of IAPs. This finding provides a new insight into the mechanism of IAP antagonist-mediated regulation of autophagy.
\end{abstract}

Keywords: IAP antagonists; GDC-0152; WX20120108; apoptosis; autophagy; carcinoma cells; Foxo3; ROS; catalase

Acta Pharmacologica Sinica (2019) 40:1466-1479; https://doi.org/10.1038/s41401-019-0253-5

\section{INTRODUCTION}

Induction of tumor cell apoptosis is considered to be an important therapeutic strategy for cancer [1]. Overexpression of X-linked inhibitor of apoptosis protein (XIAP) and cellular IAP1/2 (cIAP1/2), the three major members of the IAP family, has been reported in a variety of cancer tissues and relevant cancer cells $[2,3]$. They inhibit apoptosis by directly or indirectly hindering the activation of caspase-3/7 (executioner caspases for apoptosis) through intrinsic and extrinsic apoptotic pathways, respectively [4-7]. Therefore, anticancer therapies that target IAPs have attracted extensive attention [8], and several small-molecule IAP antagonists mimicking the endogenous antagonist Smac (second mitochondria-derived activator of caspases) protein have been designed and synthesized. Among these molecules, GDC-0152, SM-406, LCL161, TL32711, and others have reached Phase I or II clinical trials [9-11].

The anticancer mechanism of the known IAP antagonists has been studied systematically since the discovery of the first antagonist. All IAP antagonists can selectively bind to the BIR domains of XIAP, CIAP1, CIAP2, or ML-IAP (melanoma inhibitor of apoptosis protein), but with different affinities. They abrogate XIAP-mediated and cIAP1/2-dependent caspase inhibition and thus increase caspase-3, caspase- 7 , and caspase- 9 activity to induce apoptosis [12]. Meanwhile, IAP antagonists induce cIAP1/2 degradation, augment TNFa-induced cell death [13], and activate the NF-KB pathway to stimulate the adaptive antitumor immune response in cancers [14]. Recently, several IAP antagonists, including embelin, GDC-0152, and APG-1387, have been reported to exhibit autophagy-regulating activity [15-25]. These IAP antagonists showed autophagy-inducing activity in different cell lines; however, the mechanisms underlying this activity appear to be different and the information available regarding them is less. Meanwhile, XIAP and cIAPs have also been found to be involved in the regulation of autophagy [26, 27]. However, the underlying regulatory mechanisms are diverse, including IAP-dependent and IAP-independent mechanisms [15].

Normally, autophagy is a cell survival pathway that plays essential roles in maintaining cellular homeostasis via degradation and recycling of damaged organelles and toxic macromolecules. However, excessive autophagy is implicated in autophagic cell death $[28,29]$. Links between autophagy and apoptotic pathways have already been validated [30]. Autophagy has been speculated to have an antiapoptotic effect; however, under some circumstances, it also demonstrates an apoptosis-promoting effect [31].

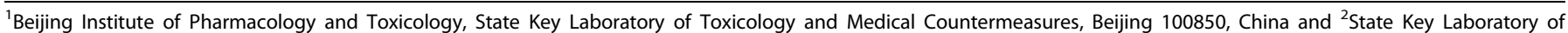
Functions and Applications of Medicinal Plants, Guizhou Medical University, Guiyang 550014, China

Correspondence: Li-li Wang (wangll63@126.com)
}

Received: 24 December 2018 Accepted: 19 May 2019

Published online: 17 July 2019 


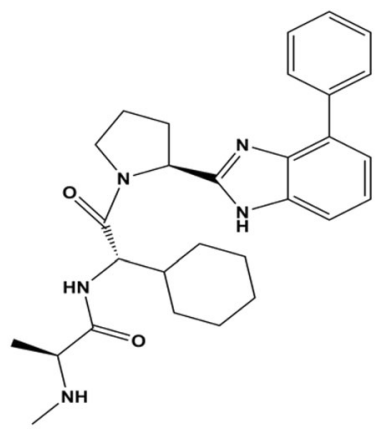

WX20120108

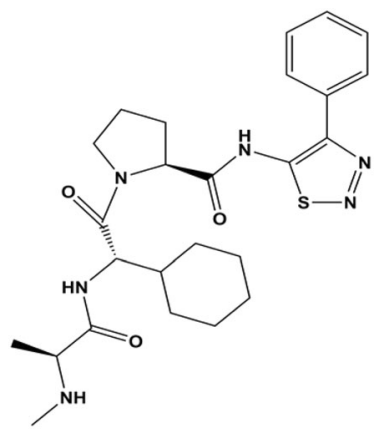

GDC-0152
Fig. 1 Chemical structures of WX20120108 and GDC-0152

Therefore, clarifying the mechanism of autophagy regulation by an IAP antagonist could not only facilitate further disclosure of the mutual relationship between apoptosis and autophagy but also contribute to the development of novel anticancer drugs.

WX20120108 is a novel IAP-targeted compound designed and synthesized at our institute. As an analogue of GDC-0152 (a known IAP antagonist, Fig. 1), WX20120108 shows more potent antitumor activity and autophagy-regulating activity in tumor cells than its parent molecule in addition to exhibiting the profile of an IAP antagonist. Here, WX20120108-mediated autophagy induction and the underlying regulatory mechanism were studied, and the ROS-FOXO pathway was confirmed as a key mediator involved in the WX20120108-induced tumor cell autophagy.

\section{MATERIALS AND METHODS}

Compounds and reagents

Compound WX20120108 was designed and synthesized in our institute. The structure (Fig. 1) was validated using nuclear magnetic resonance/mass spectrometry ( $\left.{ }^{1} \mathrm{H}-\mathrm{NMR} / \mathrm{MS}\right)$, and the purity (>98\%) was determined via high-performance liquid chromatography.

GDC-0152 (Cat. no. S7010, Fig. 1) and wortmannin (S2758) were purchased from Selleck (TX, USA). Z-VAD-FMK (ab120382) was purchased from Abcam (MA, USA). Chloroquine (CQ, P36235) was purchased from Thermo Scientific (MA, USA). Catalase was purchased from Beyotime (Shanghai, China).

Hoechst 33342 (H21492), rabbit antibodies against human LC3B (L10382), donkey anti-rabbit Alexa Fluor 488 (A21206) and donkey anti-mouse Alexa Fluor 546 (A10036) secondary antibodies were purchased from Life Technologies (CA, USA). Rabbit antibodies against human Foxo3 (2497), caspase-3 (9662), and cleaved caspase-3 (9664) were purchased from CST (MA, USA). Mouse antibodies against human p62 (ab109012) were purchased from Abcam. Rabbit antibodies against human XIAP (sc-11426), cIAP1 (sc-7943), and cIAP2 (sc-7944) were purchased from Santa Cruz (Texas, USA). The Alexa Fluor 488 Annexin V/Dead Cell Apoptosis Kit (V13241) and CM- $\mathrm{H}_{2}$ DCFDA (C6827) were purchased from Thermo Scientific. The cathepsin B (CTSB) (K140-100) and cathepsin D (CTSD) (K143-100) activity assay kits were purchased from BioVision (CA, USA). Mouse antibodies against human GAPDH, horseradish peroxidase-labeled goat anti-rabbit (ZB2301) and goat anti-mouse (ZB-2305) secondary antibodies were purchased from ZSGB-Bio (Beijing, China).

Cell lines and culture conditions

HepG2, HeLa, Skov3, MDA-MB-231, and HLF cells were purchased from the Basic Medical Center of the Institute of Basic Medical Sciences, Chinese Academy of Medical Sciences (Beijing, China). HeLa-bcl 2 and Skov3/T cells were established and cultured in our laboratory. HeLa, HeLa-bcl2, MDA-MB-231, and HLF cells were cultured in RPMI-1640 medium (GIBCO, USA) at $37^{\circ} \mathrm{C}$ in a humidified $5 \% \mathrm{CO}_{2}$ incubator. HepG2, Skov3, and Skov3/T cells were maintained in high-glucose Dulbecco's modified Eagle's medium (DMEM, GIBCO, USA). All media were supplemented with $10 \%$ fetal bovine serum (FBS, GIBCO, USA), $100 \mathrm{U} / \mathrm{mL}$ penicillin-streptomycin-ampicillin, and for Skov3/T cells, 10 nmol/L Taxol (Merck, Darmstadt, Germany) was added. Fluorescently labeled reporter cell lines were purchased from Thermo Scientific, except for the Akt1-EGFP_CHO cell line, which was purchased from GE Healthcare (Fairfield, CT, USA). All cell lines were cultured following the manufacturer's recommendation. To be specific, Foxo3-EGFP_U2OS cell lines were cultured in DMEM supplied with $10 \%$ FBS and $1 \%$ G418.

Docking methodology

Molecular docking was performed using the program Discovery Studio from BIOVIA Inc. (San Diego, CA, USA). Discovery Studio (http://www.3dsbiovia.com/products/collaborative-science/bioviadiscovery-studio/) is an exhaustive flexible docking algorithm with a scoring function that incorporates both empirical and knowledge-based features and was used for active site detection and docking. The pictures were attained via PyMOL (V 2.0) from DeLano Scientific LLC (San Carlos, CA, USA).

FPA competition assay

The binding affinities of WX20120108 for XIAP BIR3, XIAP BIR2BIR3, and CIAP1/2 BIR3 were determined using a fluorescence polarization anisotropy (FPA) competition assay developed by the Wang laboratory [32]. Primarily, $5 \mu \mathrm{L}$ of various concentrations of WX20120108 was added to each well of black 96-well roundbottom plates (Microfluor 2, Thermo Scientific) and then incubated with $120 \mu \mathrm{L}$ assay buffer $(100 \mathrm{mmol} / \mathrm{L}$ potassium phosphate, $\mathrm{pH} 7.5 ; 100 \mu \mathrm{g} / \mathrm{mL}$ bovine $\gamma$-globulin; $0.02 \%$ sodium azide, Invitrogen) containing target protein and SM-F2 (a fluorescently tagged compound that specifically binds to the BIR3 domain) at room temperature for $2-3 \mathrm{~h}$ with gentle shaking. The polarization values in millipolarization units were measured at an excitation wavelength of $485 \mathrm{~nm}$ and an emission wavelength of $530 \mathrm{~nm}$ using an Infinite M-1000 plate reader (Tecan U.S., Research Triangle Park, NC). For each experiment, the concentrations of target protein and SM-F2 in different target protein competitive binding tests were determined according to a previous study [33], and each 96-well plate had a negative control and a positive control group. The negative control group contains the complex of protein and compound SM-F2, which has an inhibitory rate of $0 \%$. The positive control group contains free protein only, and the inhibitory rate equals $100 \%$. The $K_{\mathrm{i}}$ value for each compound was calculated based upon the $I C_{50}$ value, the $K_{\mathrm{d}}$ value of the protein-probe complex, and the concentrations of the protein and probe in the competition assay, using a previously reported algorithm and the associated computer program [34]. The equation is $K_{\mathrm{i}}=\left[I_{50} /\left([L]_{50} / K_{\mathrm{d}}+[P]_{0} / K_{\mathrm{d}}+1\right)\right.$, in which $[I]_{50}$ denotes the concentration of the free inhibitor at $50 \%$ inhibition, $[L]_{50}$ is the concentration of SM-F2 at $50 \%$ inhibition, $[P]_{0}$ is the concentration of the free protein at $0 \%$ inhibition and $K_{d}$ is the dissociation constant of the protein-SM-F2 complex. The $\mathrm{IC}_{50}$ value, the inhibitor concentration at which $50 \%$ of the bound tracer was displaced, was determined from the plot using nonlinear least-squares analysis. Curve fitting was performed using Prism software (GraphPad Software, Inc., San Diego, CA, USA) [34].

Antiproliferative activity assay

A sulforhodamine B (SRB) assay was used to assess the antiproliferative activity of the tested compounds [35]. Briefly, tumor cells $\left(2.5 \times 10^{3}-5.0 \times 10^{3}\right.$ cells/well depending on cell type) were seeded into 96-well plates and cultured overnight before compound exposure. After $72 \mathrm{~h}$ of compound treatment, the cells 
were fixed with trichloroacetic acid (TCA, 10\%) at $4{ }^{\circ} \mathrm{C}$ for $1 \mathrm{~h}$, washed with double-distilled water five times and dried at room temperature. Then, the cells were dyed with SRB $(0.4 \%$ in $1 \%$ acetic acid) at room temperature for $30 \mathrm{~min}$, washed with $1 \%$ acetic acid five times, and dried at room temperature successively. Finally, $10 \mathrm{mmol} / \mathrm{L}$ Tris base solution was added, and the absorbance at $510 \mathrm{~nm}$ was measured in the microplate reader (EL800, Bio-TEK, USA). The data were processed as described [36]. The results were expressed as the means \pm SD of at least three independent experiments. The antiproliferative activity was expressed as the inhibitory rate. The inhibitory rate $(\%)=$ $\left(A_{\text {control,72 h }}-A_{\text {compound, } 72 \mathrm{~h}}\right) /\left(A_{\text {control,72 h }}-A_{\text {control, } \mathrm{h}}\right) \times 100$, where $A$ is the absorbance at $510 \mathrm{~nm}$.

FCM analysis

To detect cellular apoptosis induced by the tested compounds, we used an Alexa Fluor 488 Annexin V/Dead Cell Apoptosis Kit. In brief, HeLa and MDA-MB-231 cells seeded in six-well plates at a density of $8 \times 10^{4}$ cells $/ \mathrm{mL}$ were cultured overnight and then treated with test compounds for $24 \mathrm{~h}$ before harvesting via centrifugation. The cells were stained with Annexin $\mathrm{V}$ and propidium iodide $(\mathrm{PI})$ according to the manufacturer's instructions and measured using a FACSCalibur Cytometer (BD Biosciences, CA, USA). Cells were classified as "survival $\left(\mathrm{PI}^{-} /\right.$Annexin $\left.\mathrm{V}^{-}\right)$", "early apoptosis $\left(\mathrm{PI}^{-} /\right.$Annexin $\left.\mathrm{V}^{+}\right)$", "late apoptosis $\left(\mathrm{PI}^{+} /\right.$Annexin $\left.\mathrm{V}^{+}\right)$", or "necrosis $\left(\mathrm{PI}^{+} /\right.$Annexin $\left.\mathrm{V}^{-}\right)$" according to the extent of staining by Annexin V or/and PI. The values of apoptotic cells (\%) were the total number of early apoptotic cells and late apoptotic cells.

\section{Cellular immunofluorescence}

Immunofluorescence staining for LC3B and Foxo3 was conducted as described below. Briefly, cells were plated in Corning 3603 plates (blackwall, clear bottom 96-well plates; Cat. no. 3603, Corning, NY, USA), treated with different compounds, fixed with $4 \%$ formaldehyde, and washed twice with $1 \times$ phosphate-buffered saline. After permeabilizing the cell membranes using $0.1 \%$ Triton X-100 and blocking with 5\% bovine serum albumin, target proteins were visualized using primary antibodies and fluorescently labeled secondary antibodies. Lysosomes were stained with $0.05 \mu \mathrm{mol} / \mathrm{L}$ LysoTracker Red before cells were fixed. Cell nuclei were labeled with $1 \mu \mathrm{mol} / \mathrm{L}$ Hoechst 33342 and subjected to image acquisition on a high-content analysis (HCA) platform or other detection systems, and the cell count was measured to reflect cell viability.

HCS for signaling pathways or target proteins

Twelve genetically modified reporter cell lines were used in cellbased signaling pathways or target protein screening. For each cell line, we followed the screening procedures recommended by the manufacturer, and the key information is briefly summarized in Fig. 6a. The concentrations of WX20120108 used for screening were $1,3,10,30$, and $100 \mu \mathrm{mol} / \mathrm{L}$. Detailed information regarding the Foxo3 assays is provided below. Foxo3-EGFP_U2OS cells (U2OS cells stably expressing the Foxo3-EGFP fusion protein) were seeded in Corning 3603 plates at a density of $6 \times 10^{3}$ cells/well for $24 \mathrm{~h}$ to allow adhesion. Then, different concentrations of WX20120108 were added, and the plates were incubated for $1 \mathrm{~h}$. Finally, cells were fixed with $4 \%$ formaldehyde, and the nuclei were dyed with $1 \mu \mathrm{mol} / \mathrm{L}$ Hoechst 33342 for $30 \mathrm{~min}$ at $37^{\circ} \mathrm{C}$. The cells were then subjected to HCA acquisition and analysis using an IN Cell Analyzer 2000 platform. The activity of WX20120108 in Foxo3 pathway assays was expressed as the activation rate relative to that of the positive compound ( $300 \mathrm{nmol} / \mathrm{L}$ wortmannin) and negative control ( $0.2 \%$ DMSO).

\section{Cathepsin activity assay}

The catalytic activity of cathepsins was determined by CTSB and CTSD activity fluorometric assay kits. Briefly, $2 \times 10^{6}$ cells were harvested by centrifugation and lysed in $200 \mu \mathrm{L}$ of chilled cell lysis buffer for $20 \mathrm{~min}$. Then, $50 \mu \mathrm{L}$ of supernatant cell lysate was collected via centrifugation at $4{ }^{\circ} \mathrm{C}$ for $5 \mathrm{~min}$ at top speed and transferred into 96-well plates, mixed with reaction buffer and substrate, and incubated at $37^{\circ} \mathrm{C}$ for $2 \mathrm{~h}$. The samples were read in a fluorometer with $400 \mathrm{~nm}$ excitation and $505 \mathrm{~nm}$ emission filters. The activity was normalized to the samples' protein concentration.

Intracellular ROS measurement

Intracellular ROS levels were measured via HCA after staining with $\mathrm{CM}-\mathrm{H}_{2}$ DCFDA as described previously [37]. Briefly, $8 \times 10^{3}$ cells were plated in black 96-well culture plates, allowed to attach overnight, and exposed to DMSO (control) or the indicated concentrations of WX20120108 for $6 \mathrm{~h}$. The cells were stained with $1 \mu \mathrm{mol} / \mathrm{L} \mathrm{CM}-\mathrm{H}_{2}$ DCFDA and $1 \mu \mathrm{mol} / \mathrm{L}$ Hoechst 33342 for $45 \mathrm{~min}$ at $37^{\circ} \mathrm{C}$, and the fluorescence was measured using an IN Cell Analyzer 2000. In some experiments, the cells were pretreated for $6 \mathrm{~h}$ with siRNA against IAPs prior to WX20120108 exposure and analysis of ROS generation. All settings were identical between the different experimental groups.

High-content image acquisition and analysis

The images were acquired with an IN Cell Analyzer 2000 (GE HealthCare, USA) under a $20 \times$ objective lens for the assays [38]. For all measurements, filters were set according to the wavelength of the fluorescent dyes, and nine fields from each well and no fewer than 200 cells were obtained. The acquired images were analyzed using an IN Cell Analyzer Workstation 3.5 and the Multi Target Analysis Module (GE Healthcare). The final measurements were averaged over the population of cells detected in the fields of view.

\section{Colocalization analysis}

HeLa cells were grown on coverslips overnight and incubated with tested compounds for a certain time. Then, lysosomes and LC3B were labeled as described above. All samples were examined under an UltraVIEW VoX confocal microscope (PerkinElmer, MA, USA) equipped with a $63 \times$ oil immersion objective. The confocal images were acquired using Improvision Volocity software. The Pearson correlation coefficient (PCC) was calculated to quantify colocalization. This calculation was performed by Volocity Demo 2.0 software between the stacks of images from two channels.

Western blotting analysis

Cells were lysed after the indicated treatments. Approximately, $40 \mu \mathrm{g}$ of total protein for each sample was separated by sodium dodecyl sulfate polyacrylamide gel electrophoresis on $10 \%$ gels and then transferred to polyvinylidene difluoride membranes. The membranes were blocked with $5 \%$ fat-free milk and incubated with the appropriate primary antibodies at $4{ }^{\circ} \mathrm{C}$ overnight, followed by incubation with horseradish peroxidase-conjugated secondary antibodies at room temperature for $1 \mathrm{~h}$. The immunostaining signal was visualized using ECL Plus reagent (Applygen, Beijing, China), imaged, and analyzed with an Alpha Imager 5500 (Alpha Innotech, San Leandro, CA, USA).

\section{Transmission electron microscopy (TEM)}

HeLa cells were seeded in 6-well plates and treated with WX20120108 for 16 h. Cells were harvested, collected and prefixed in $2.5 \%$ glutaraldehyde overnight at $4{ }^{\circ} \mathrm{C}$. The samples were then postfixed, dehydrated, embedded, sectioned, and stained as previously described [39]. Finally, electron micrographs were captured using a transmission electron microscope.

\section{Quantitative polymerase chain reaction}

HeLa cells were exposed to the WX20120108 (30 $\mu \mathrm{mol} / \mathrm{L})$ for the indicated times. Total RNA was extracted using a BioTeke Total RNA Extraction Kit (Cat. no. RP1201, BioTeke, Beijing, China). RNA 
was then reverse transcribed into single-stranded CDNA using TransScript SuperMix (Cat. no. AT311-03, TransGen, Beijing, China). The resulting CDNA was used as a template for quantitative polymerase chain reaction (qPCR). The primers used in this study are listed in Table 1. qPCR was conducted using the ABI Prism 7900 sequence detection system (Applied Biosystems, Foster City, CA, USA), as previously described [40]. The relative change in mRNA levels was determined using the $2^{-\triangle \Delta C T}$ method, and $\beta$-actin was used as the internal standard.

Small interfering RNA (siRNA) and transient transfection

The scrambled RNAi oligonucleotides and siRNAs targeting Foxo3, $X I A P$, CIAP1, and CIAP2 (GenePharma, Shanghai, China) were transfected into HeLa cells using Lipofectamine RNAiMAX (Cat. no. 13778-150, Invitrogen) according to the manufacturer's protocol. The siRNA sequences were as follows: Foxo3, 5'-CA AGCACAGAGUUGGAUGATT-3'; XIAP, 5'-GGUCAGUACAAAGUUGAA ATT-3'; CIAP1, 5'-CCCUACAGUUAUGCAAUGATT-3'; CIAP2, 5'-CGUG GCUCUUAUUCAAACUTT- $3^{\prime}$. After the designated treatments, cell lysates were prepared for Western blotting.

Data processing and statistical analysis

All data from the in vitro experiments were expressed as the means $\pm S D$ of three independent experiments. $I C_{50}$ values were calculated with Origin 6.1 software. Statistical analyses were performed using one-way analysis of variance (ANOVA) with GraphPad Prism 5 software $\left({ }^{*} P<0.05,{ }^{* *} P<0.01,{ }^{* * *} P<0.001\right)$.

\section{RESULTS}

WX20120108 binds to the BIR3 domains of CIAP1, CIAP2, and XIAP with high affinity

Based on the key structural features of the XIAP-BIR3 domain interacting with Smac-Ala-Val-Pro-lle (AVPI, the binding peptide of endogenous IAP antagonist Smac), WX20120108 was designed. Docking results of this compound with XIAP-BIR3, as shown in Fig. 2a, b, indicated that WX20120108 inserts well in the pockets of XIAP-BIR3, and several hydrogen bonds with W323, E314, T308, and Q319 residues in the backbone of BIR3 were formed, which were previously also observed in the binding mode of Smac-AVPI [41].

An FPA competitive binding experiment was used to further analyze the binding ability of WX20120108 with XIAP BIR3, XIAP BIR2-BIR3, or CIAP1/2 BIR3 domains. Saturation binding experiments were performed to determine the binding affinity of the fluorescent probes to the IAP constructs of interest, as reported [33]. As shown in Table 2, WX20120108 displayed high affinities with XIAP BIR3, XIAP BIR2-BIR3, CIAP1 BIR3, and CIAP2 BIR3 domains. Meanwhile, the $I C_{50}$ values of WX20120108 on the competitive inhibitor SM-F2 for the BIR3 domains of CIAP1 and CIAP2 were comparable and were slightly higher than that for XIAP-BIR3. These data showed that WX20120108 binds to CIAP1, CIAP2, and XIAP with high affinity.

WX20120108 inhibits the proliferation of cancer cells The anticancer activity of WX20120108 was first screened in HepG2, Skov3, Skov3/T, MDA-MB-231, HeLa, and HeLa-bcl2 cancer cell lines by detecting the antiproliferative activity of WX20120108 using an SRB assay. Compared to GDC-0152, the IAP antagonist that has been entered into phase I clinical trial, WX20120108 exhibited stronger inhibitory activity in all tested cancer cell lines (Table 3); the potency of WX20120108 was two to tenfold higher than that of GDC-0152. In contrast to the differential antiproliferative effect of GDC-0152 on these cancer cells, WX20120108 showed nearly comparable potency except on the HeLa-bcl2 cells. Moreover, both GDC-0152 and WX20120108 exhibited reduced cytotoxicity in human lung fibroblast (HLF) cells; the $I C_{50}$ values were higher than those in the tested cancer cells.

WX20120108 exhibits the anticancer properties typical of IAP antagonists

Overexpression of IAPs has been correlated with certain types of advanced progressive cancer, poor prognosis, or low response to treatment $[42,43]$, and IAP antagonists are currently under clinical considerations for these solid cancers (e.g., cervical and breast cancers) [11]. Herein, HeLa and MDA-MB-231 cells were chosen as the target cells for validating the IAP antagonist-like characteristics

Table 1. The primers used in quantitative real-time PCR

\begin{tabular}{lll}
\hline & Sense & Antisense \\
\hline p62 & $5^{\prime}$-GAACTCCAGTCCCTACAGATGCC-3' & $5^{\prime}$-CGGGAGATGTGGGTACAAGG-3' \\
Bnip3 & $5^{\prime}$-CGCAGACACCACAAGATACCA-3' & $5^{\prime}$-CGATGGCCAGCAAATGAGAG-3' \\
PIK3C3 & $5^{\prime}$-GCCTCTTCCTCCACCAATGAA-3' & $5^{\prime}$-CCACTGCAGCAAAAAGAGCAT-3' \\
Atg4B & $5^{\prime}$-CTCATCTACCTGGACCCCCA-3' & $5^{\prime}$-TCGAAGAATCTTTCCAGTCGCT-3' \\
Atg5 & $5^{\prime}$-TGCAAAATGACAGATTTGACCAGT-3' & $5^{\prime}$-CCGGGTAGCTCAGATGTTCA-3' \\
$\beta$-actin & $5^{\prime}$-TAAAGACCTCTATGCCAACACAGT-3' & $5^{\prime}$-CACGATGGAGGGGCCGGACTCATC-3' \\
\hline
\end{tabular}
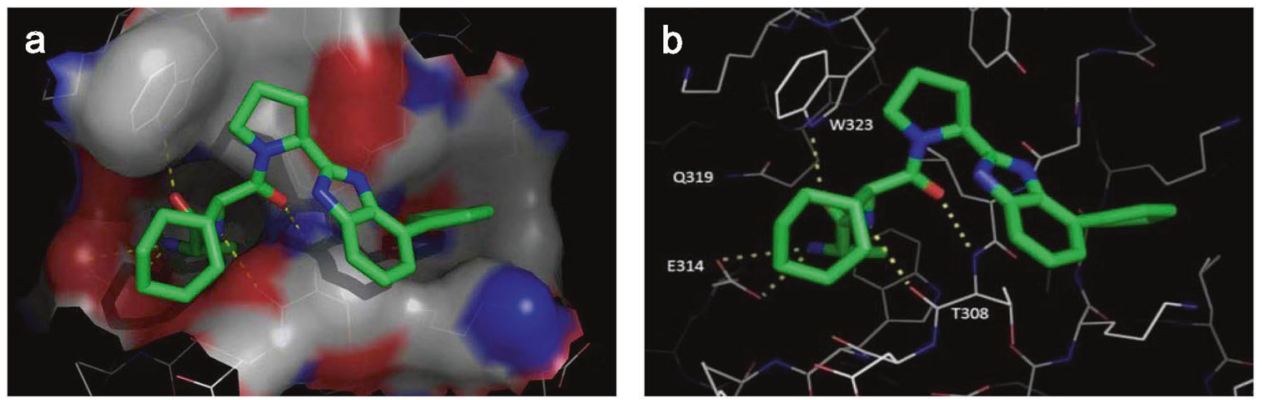

Fig. 2 WX20120108 (shown as sticks) docked with XIAP-BIR3 in the surface mode (a) and in the wire frame mode (b). Hydrogen bonds are shown in yellow dashed lines in (a) and (b) 
Table 2. Biophysical effects of WX20120108 and IAP protein interaction (nmol/L)

\begin{tabular}{|c|c|c|c|c|c|c|c|c|}
\hline & \multicolumn{2}{|c|}{ XIAP BIR3 } & \multicolumn{2}{|l|}{ CIAP1 BIR3 } & \multicolumn{2}{|l|}{ ClAP2 BIR3 } & \multicolumn{2}{|c|}{ XIAP BIR2-BIR3 } \\
\hline WX20120108 & $206 \pm 39$ & $69.0 \pm 13.5$ & $31.9 \pm 7.2$ & $5.6 \pm 1.4$ & $28.4 \pm 11.0$ & $6.9 \pm 3.0$ & $77.2 \pm 4.1$ & $19.0 \pm 1.0$ \\
\hline
\end{tabular}

Table 3. IC $\mathrm{IC}_{50}$ of WX20120108 in different cell lines

\begin{tabular}{|llllllcc}
\hline & \multicolumn{7}{c}{ IC $_{50}(\mu \mathrm{mol} / \mathrm{L})$} \\
\cline { 2 - 7 } & HepG2 & Skov3 & Skov3/T & MDA-MB-231 & HeLa & HeLa-bcl2 & HLF \\
\hline GDC-0152 & $78.95 \pm 8.40$ & $28.16 \pm 3.31$ & $123.18 \pm 6.03$ & $22.40 \pm 6.55$ & $25.10 \pm 7.50$ & $60.12 \pm 9.32$ & $114.53 \pm 11.37$ \\
WX20120108 & $11.98 \pm 3.70$ & $12.33 \pm 2.28$ & $12.49 \pm 2.47$ & $14.37 \pm 1.49$ & $12.72 \pm 4.46$ & $26.92 \pm 5.15$ & $42.12 \pm 3.09$ \\
\hline \multicolumn{6}{l}{ Cells were treated with different compounds for $72 \mathrm{~h}$ then assayed using SRB method. Values are means \pm SD, $n=3$} \\
\hline
\end{tabular}

of WX20120108. First, flow cytometry (FCM) following Annexin VFITC/PI dual labeling showed that WX20120108 increased the proportion of apoptotic and dead cells in these two cell lines in a dose-dependent manner (Fig. 3a), and this effect was found to be almost completely counteracted by cotreatment with the pancaspase inhibitor Z-VAD-FMK (Fig. 3b). Second, Western blotting assays indicated that WX20120108 reduced the levels of IAPs, especially CIAP1, in a dose-dependent manner (Fig. 3c). p-NF-KB and p-IKB-a levels were increased after $\sim 0.5-6 \mathrm{~h}$ of WX20120108 treatment (Fig. 3d), and cleaved caspase-3 levels increased in a dose-dependent manner after $24 \mathrm{~h}$ of WX20120108 treatment (Fig. 3e). Finally, WX20120108-mediated promotion of the TNFainduced cell death pathway was validated using a cell survival experiment with HCA. WX20120108 significantly reduced the number of viable cells when cotreated with TNFa (Fig. $3 f$ ), which is consistent with previous reports that IAP antagonists synergistically promote TNFa-induced cell death $[13,44]$. In addition, in accordance with the above results, Z-VAD-FMK supplementation also rescued the TNFa-induced reduction in cell viability (Fig. 3f). The above results indicated that WX20120108 promotes caspasedependent apoptosis mainly through the CIAP and TNFa pathways and exhibits the same cancer cell inhibitory profile as typical IAP antagonists.

WX20120108 regulates cancer cell autophagy in a dose- and timedependent manner

The impact of WX20120108 on autophagy was further studied in HeLa and MDA-MB-231 cells using fluorescence image-based HCA, Western blot, and transmission electron microscopy (TEM). Similar to the autophagy inhibitor CQ, WX20120108 apparently increased the green fluorescence intensity and puncta number of antibodylabeled LC3B (as shown in Fig. 4a), which is visualized either as the cytoplasmic localization or as punctate structures that primarily represent autophagosomes $[45,46]$. Quantitative analysis indicated that WX20120108 can increase the content of LC3B puncta in a dose- and time-dependent manner in both HeLa and MDAMB-231 cells (Fig. 4a). However, the number of cells decreased as the concentrations of WX20120108 increased, particularly from 3 to $30 \mu \mathrm{mol} / \mathrm{L}$. There was a drastic increase in LC3B puncta and a dramatic decrease in cell viability after $20 \mathrm{~h}$ incubation, which suggested that a dynamic "switch" from autophagy to cell death occurred with the increase in WX20120108 concentration and incubation time. Corroborating the HCA results, Western blotting confirmed that WX20120108 treatment led to significantly increased formation of LC3B-II in a dose- and time-dependent manner; meanwhile, p62 was also increased in both cells (Fig. 4b). It is noteworthy that the mRNA levels of p62 also increased with prolonged WX20120108 incubation time (Fig. 4c). More importantly, autophagosomes were observed in WX20120108-treated HeLa cells (Fig. 4d). These results clearly demonstrated that WX20120108 regulated autophagy in HeLa and MDA-MB-231 cells.

WX20120108 induces autophagic flux

The impact of WX20120108 on autophagic flux was assayed to further elucidate the mechanism by which WX20120108 modulates autophagy, as both the induction and the suppression of autophagy can lead to an increase in the abundance of LC3B and autophagosomes [47]. In the presence of CQ, the formation of LC3B-II was significantly enhanced in HeLa and MDA-MB-231 cells after WX20120108 treatment for 6 and $16 \mathrm{~h}$, respectively (Fig. 5a). The colocalization of autophagosomes and lysosomes revealed that WX20120108-treated cells exhibited a significant degree of fusion of autophagosomes and lysosomes. In contrast, there was almost no fusion of the fluorescent signals for autophagosomes and lysosomes in CQ-treated cells, which is consistent with the autophagic flux blocker characteristics of CQ. RGB profile analysis by ImageJ (V 1.8.0) and PCC values further confirmed the confocal microscopy results (Fig. 5b). The PCC value of CQ-treated cells $(0.28 \pm 0.01)$ was significantly lower than that of the control group $(0.32 \pm 0.02)(P<0.05)$, whereas it was much higher in the WX20120108 treatment group $(0.59 \pm$ $0.05)$ than that of the control group $(P<0.001)$, indicating that colocalization was abolished by $C Q$ treatment, while WX20120108 treatment induced colocalization. Since the p62 level increased in the above experiment, the activities of the major lysosomal proteases CTSB and CTSD were further assayed using the fluorometric assay to investigate whether WX20120108 regulates autophagy at this stage. Both CTSB and CTSD activity levels were increased in a time-dependent manner upon WX20120108 treatment in HeLa and MDA-MB-231 cells (Fig. 5C). Taken together, these results suggest that WX20120108 induces autophagic flux.

WX20120108 selectively activates FOXOs, especially Foxo3 Given that WX20120108 induced autophagy, the main signaling pathways or target proteins related to autophagy were screened on twelve EGFP-labeled reporter cell lines representing different signaling pathways or targets in an unbiased screening assay using HCA. The $Z^{\prime}$ factors for these assays were greater than 0.5, confirming that these cellular models were eligible for highcontent screening (HCS) and that the screening system was reliable [48]. Apart from the weak disturbance in phosphatidylinositol 3kinase (PI3K)-Foxo1, PI3K-Foxo3, PI3K-Foxo4, and PI3K-FYVE pathway assays, 30 and $100 \mu \mathrm{mol} / \mathrm{L}$ GDC-0152 showed almost no effect in the 
a

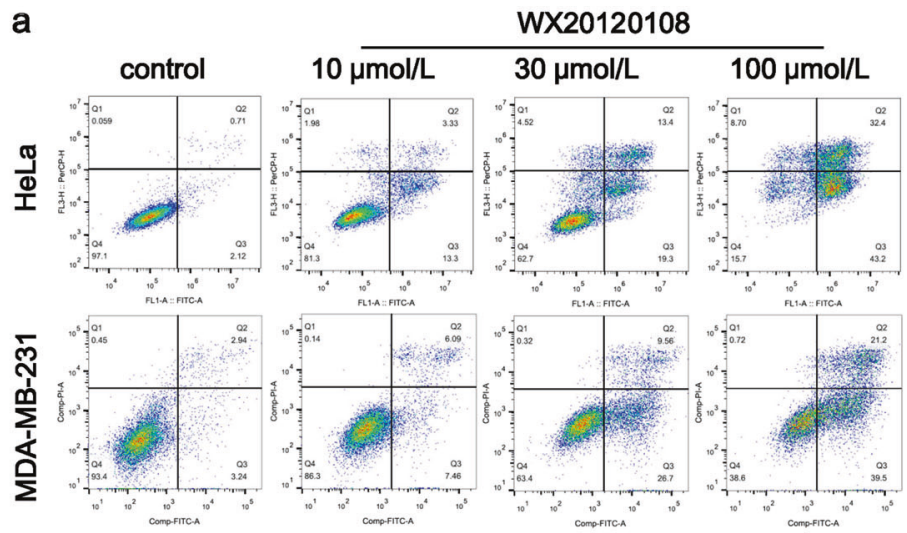

b

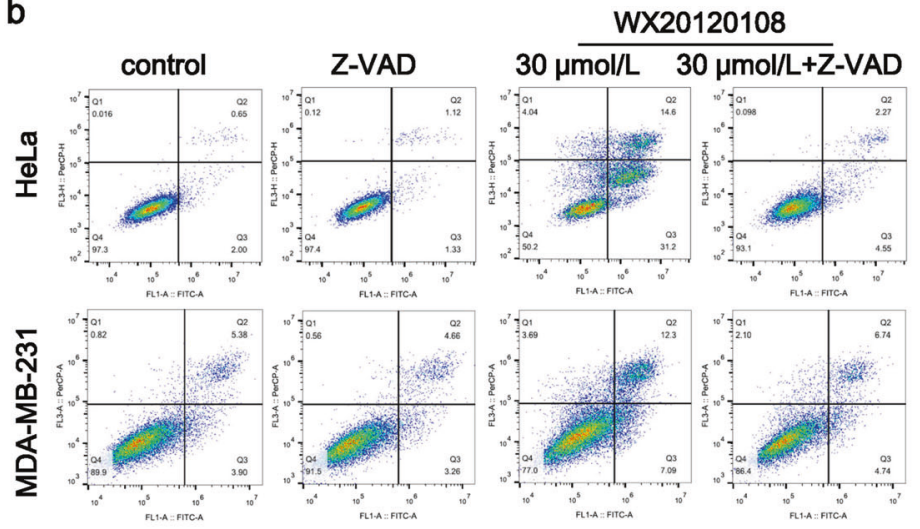

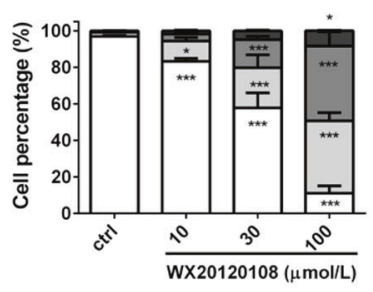
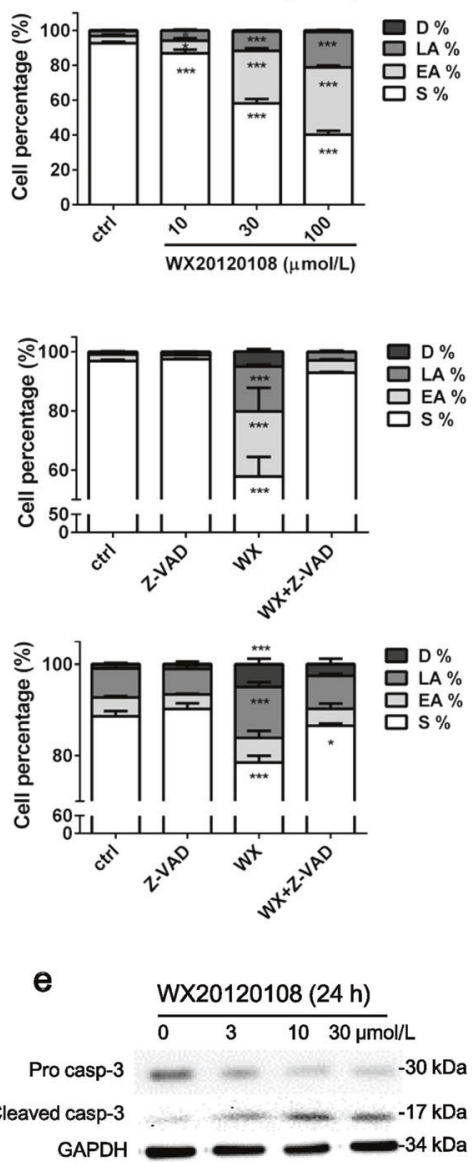

\section{믄 우}

吕 $\mathrm{EA} \%$

口
C

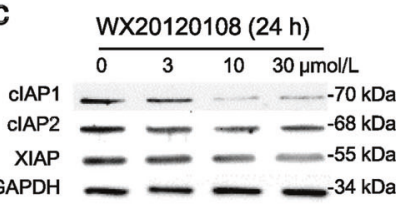

f

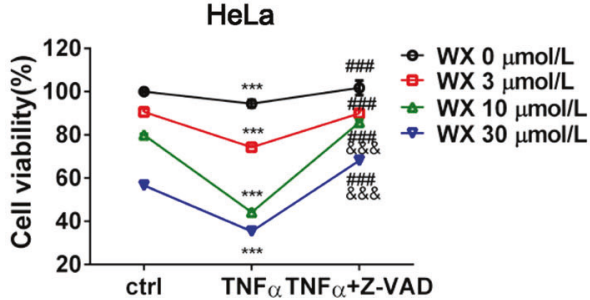

d control WX20120108 $0 \overline{526 \mathrm{~h}} \overline{0.526 \mathrm{~h}}$ p-NF-KB $-----65 \mathrm{kDa}$

$\mathrm{NF-KB}--1-65 \mathrm{kDa}$ $\mathrm{p}-\mathrm{kBB}-\alpha-1--10 \mathrm{kDa}$

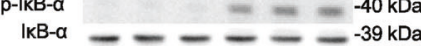
${ }_{\mathrm{GAPDH}}= \pm= \pm= \pm-39 \mathrm{kDa}$ 
a
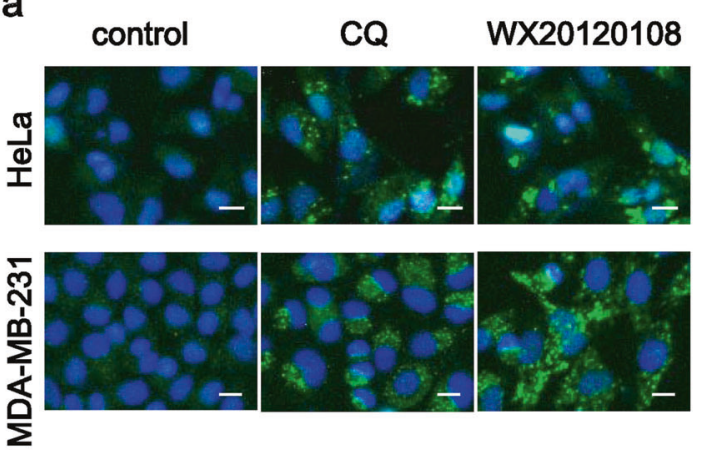
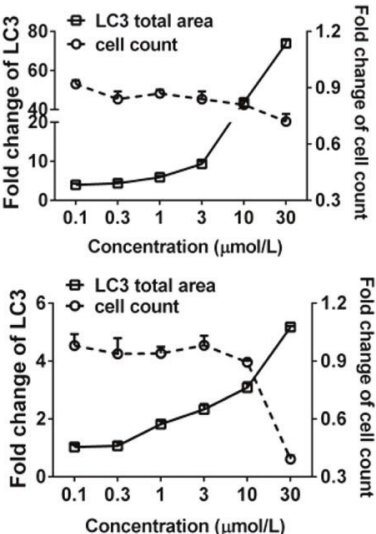
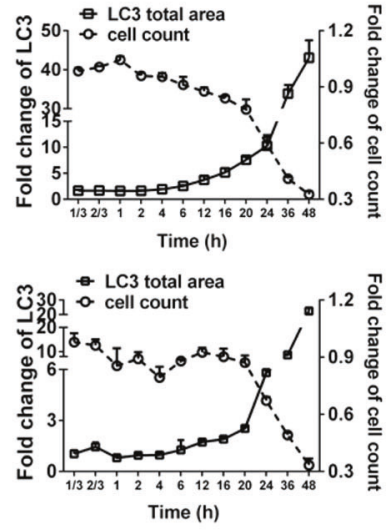

b
HeLa

WX20120108 ( $\mu \mathrm{mol} / \mathrm{L})$

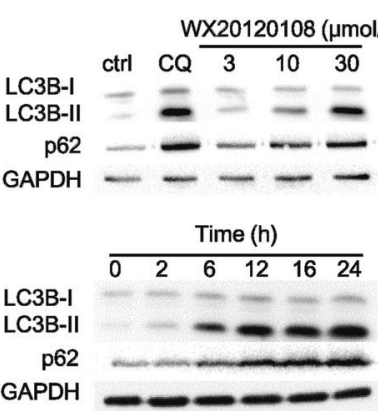

MDA-MB-231
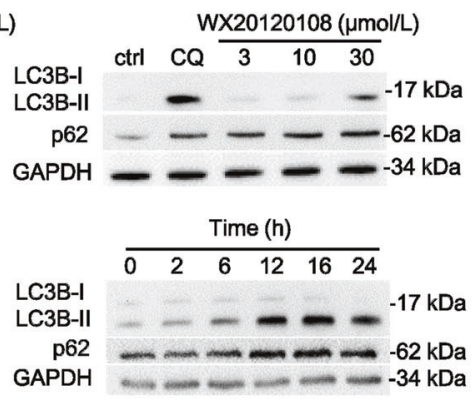

C

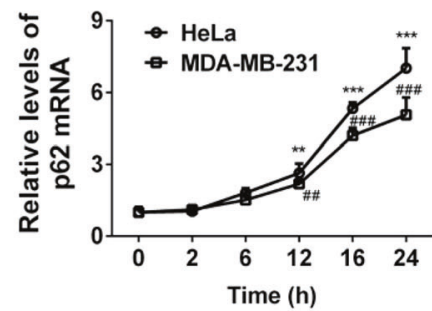

d
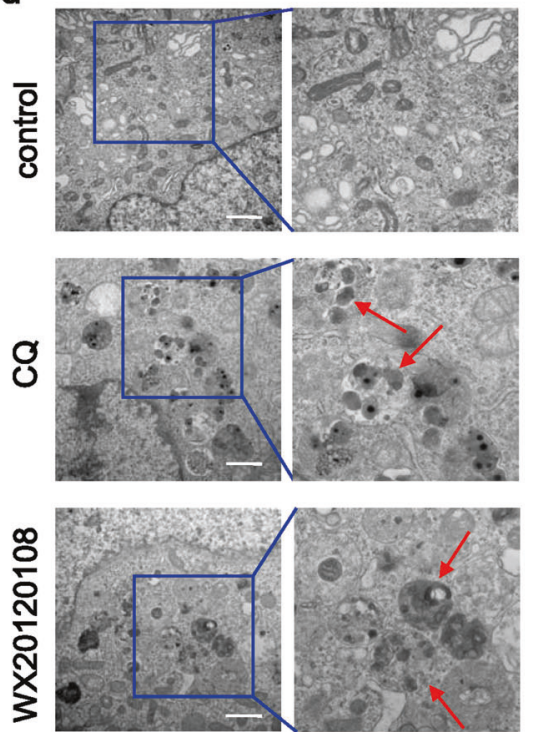

Fig. 4 WX20120108 affects autophagy in tumor cells assayed by HCA (a), Western blotting analysis (b), qPCR (c), and transmission electron microscopy (d). a Typical image of LC3B puncta accumulation (treatment for $16 \mathrm{~h}$ ) and quantitative analysis of dose- and time-dependent effects of WX20120108 in HeLa and MDA-MB-231 cells using HCA. The total intensity of LC3B puncta and the cell count reflect the status of autophagy and cell death, respectively. Scale bar $=10 \mu \mathrm{m}$. b LC3B-II and p62 protein examined by Western blotting in HeLa or MDA-MB-231 cells treated with different concentrations of WX20120108 $(3,10$, and $30 \mu \mathrm{mol} / \mathrm{L})$ for $16 \mathrm{~h}$ or $30 \mu \mathrm{mol} / \mathrm{L}$ WX20120108 over a certain time period $(2,6,12,16$, and $24 \mathrm{~h})$. GAPDH was used as a loading control. c Relative $p 62$ mRNA levels (compared with ACTIN) in HeLa and MDA-MB-231 cells treated with $30 \mu \mathrm{mol} / \mathrm{L}$ WX20120108 for different time periods were analyzed by quantitative RT-PCR. d Typical transmission electron microscopy images after treatment of HeLa cells with $30 \mu \mathrm{mol} / \mathrm{L}$ WX20120108 or $60 \mu \mathrm{mol} / \mathrm{L}$ CQ for $16 \mathrm{~h} .{ }^{*} P<0.05,{ }^{* *} P<0.01,{ }^{* * *} P<0.001 \mathrm{vs}$

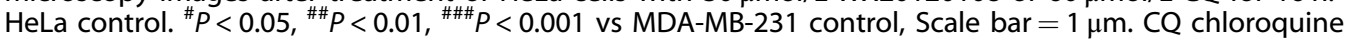

other eight cell lines (Fig. 6a). Similarly, treatment with 3 and 30 $\mu \mathrm{mol} / \mathrm{L}$ WX20120108 did not affect the majority of signaling pathways or target proteins, except for PI3K-Foxo3, PI3K-Foxo1, $\mathrm{PI} 3 \mathrm{~K}-\mathrm{FoxO} 4$, and PI3K-FYVE. Significant dose-dependent effects were observed in the PI3K-Foxo3 pathway after WX20120108 treatment (Fig. 6a, b); the $\mathrm{EC}_{50}$ value was $28.87 \pm 4.87 \mu \mathrm{mol} / \mathrm{L}$. Since PI3K-PDK, PI3K-Rac1, and PI3K-Ras were not affected by WX20120108, the FOXO activation, particularly Foxo3 nuclear translocation, was speculated to be the selective action of WX20120108. To further investigate whether this effect exists in tumor cells, the same assay was performed in HeLa cells using immunofluorescence staining with anti-Foxo3 antibody to label Foxo3 (Fig. 6c). As expected, WX20120108 promoted the nuclear translocation of Foxo3 in HeLa cells and dose-dependently induced Foxo3 activation without significantly affecting cell viability at concentrations less than $10 \mu \mathrm{mol} / \mathrm{L}$, which suggested that WX20120108-induced Foxo3 activation is an early and selective event.

WX20120108-induced autophagy depends on Foxo3 activation It has already been demonstrated that FOXO activation is involved in autophagy induction via the upregulation of the expression of downstream target genes, such as Bnip3, Pik3c3, Atg $4 b$, and Atg5, which are relevant to the formation of the autophagy initiation complex $[49,50]$. To confirm the role of Foxo3 in WX20120108-mediated autophagy, Foxo3 expression was knocked down in HeLa cells using the RNAi technique. As expected, LC3B puncta and LC3B-II protein levels were reduced remarkably (Fig. 7a, b), indicating that Foxo3 knockdown markedly reduced WX20120108-induced autophagy. Moreover, WX20120108 time-dependently increased the expression of genes 
a

HeLa

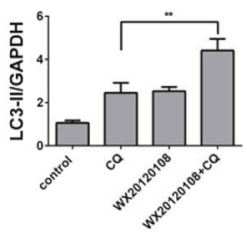

CQ $\frac{\text { ctrl }}{-+} \frac{\mathrm{WX}(16 \mathrm{~h})}{-+}$
LC3B-I
LC3B-II $--17 \mathrm{kDa}$
GAPDH $---34 \mathrm{kDa}$

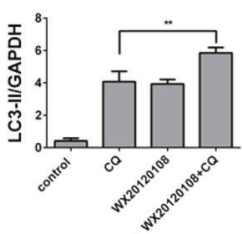

MDA-MB-231
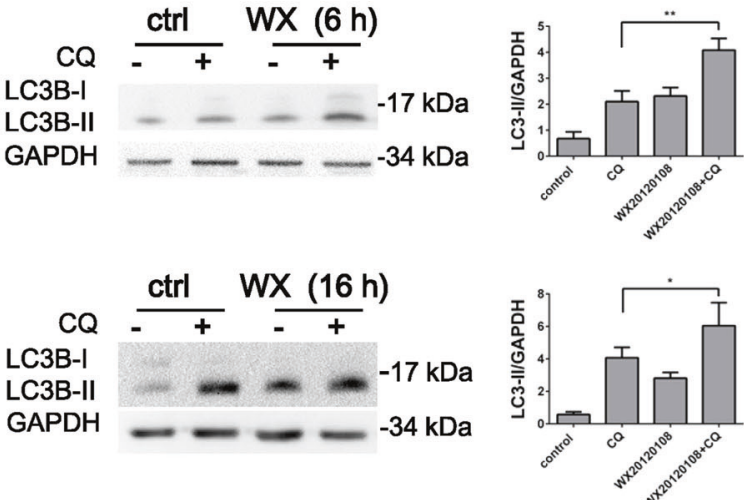

b

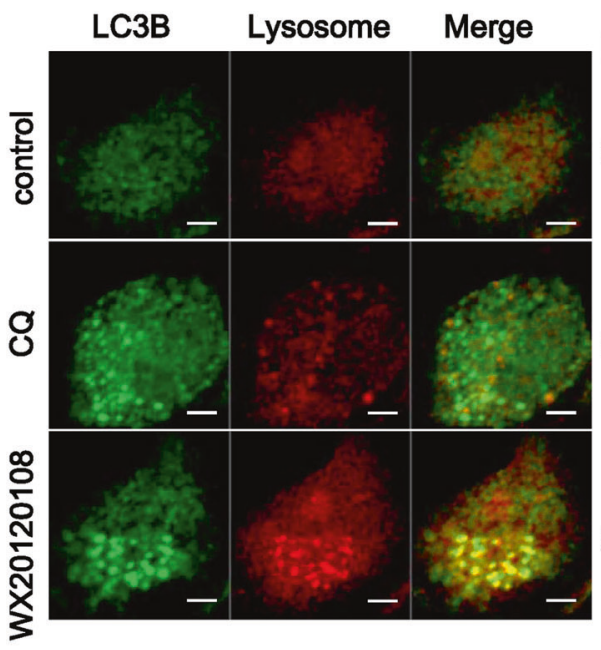

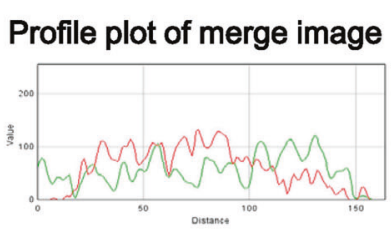
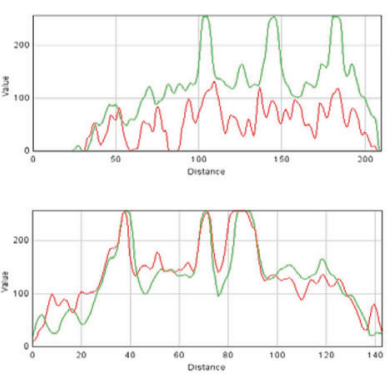

C HeLa

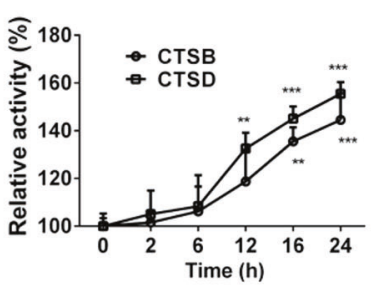

MDA-MB-231

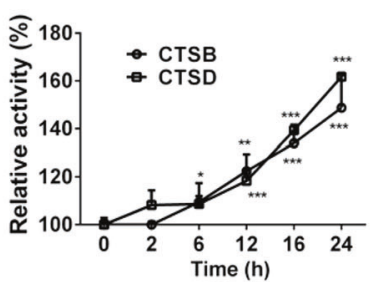

Fig. 5 WX20120108 promotes autophagic flux. a WX20120108 $(30 \mu \mathrm{mol} / \mathrm{L})$ significantly increased the LC3B-II level in the presence of $60 \mu \mathrm{mol} / \mathrm{L}$ CQ in HeLa and MDA-MB-231 cells after treatment for $6 \mathrm{~h}$ (up) or $16 \mathrm{~h}$ (down) as analyzed by Western blotting. FluorChem 5500 densitometric analysis of the LC3B-II/GAPDH ratio obtained from LC3B immunoblots (mean \pm SD of three independent experiments). ${ }^{*} P<0.05, * * P<0.01$. b Typical cell images of colocalization of LC3B (green, labeled by primary anti-LC3B antibody and Alexa Fluor 488-conjugated secondary antibody) and lysosomes (red, stained with LysoTracker Red) using an UltraVIEW VoX confocal microscope and colocalization analysis by the RGB profiler in ImageJ software (V1.8.0) after treatment of HeLa cells with $30 \mu \mathrm{mol} / \mathrm{L}$ WX20120108 or $60 \mu \mathrm{mol} / \mathrm{L} \mathrm{CQ} \mathrm{for} 16 \mathrm{~h}$. Scale bar $=2 \mu \mathrm{m}$. c WX20120108 upregulates lysosomal cathepsins. Enzymatic activity of CTSB and CTSD in WX20120108-treated HeLa cells. Cells were treated with DMSO or WX20120108 $(30 \mu \mathrm{mol} / \mathrm{L})$ at 2, 4, 6, 12, 16, and $24 \mathrm{~h}$, as indicated. Enzymatic activity was analyzed by fluorogenic kits. Data are presented as the mean \pm SD from three independent experiments and analyzed using Student's $t$ test $\left({ }^{*} P<0.05,{ }^{* *} P<0.01,{ }^{* * *} P<0.001\right)$

involved in the induction of the autophagic pathway (Bnip3 and Pik3c3) and the formation of autophagosomes (Atg4b and Atg5), which occurred as early as $2 \mathrm{~h}$ after WX20120108 treatment (Fig. 7c). Taken together, these data suggest that Foxo3 is an essential regulator of cellular autophagy induced by WX20120108.

\section{WX20120108-mediated Foxo3 activation depends on ROS} production

While searching for the reason behind the induction of Foxo3 by WX20120108, we first examined the impact of IAPs. Knockdown of $X I A P, C I A P 1$, and $C I A P 2$ did not affect WX20120108-induced Foxo3 nuclear translocation (Fig. 8a, b), indicating that the target proteins of WX20120108 were not involved in Foxo3 activation. Then, the upstream regulator of Foxo3 activation was explored. We assessed intracellular ROS generation after WX20120108 treatment via $\mathrm{HCA}$ using $\mathrm{CM}-\mathrm{H}_{2}$ DCFDA, an indicator for ROS, which is cleaved by nonspecific cellular esterases and is oxidized in the presence of peroxides to yield fluorescent $2^{\prime}, 7^{\prime}$-dichlorofluorescein (DCF) [51]. The results showed that WX20120108 significantly induced ROS generation in HeLa cells in a dose-dependent manner (Fig. 8c). Moreover, the known ROS scavenger catalase almost completely blocked WX20120108 induced-Foxo3 nuclear translocation (Fig. 8d, e) and suppressed the LC3B-II formation induced by WX20120108 (Fig. 8f). In addition, knockdown of XIAP or CIAP1 and CIAP2 did not affect ROS release induced by $30 \mu \mathrm{mol} / \mathrm{L}$ WX20120108 (Fig. 8g). These results indicated that WX20120108-induced Foxo3 activation depends on ROS but not XIAP or CIAP1 and CIAP2.

\section{DISCUSSION}

Several studies have demonstrated that small-molecule IAP antagonists induce tumor cell apoptosis by binding to IAPs, particularly XIAP, CIAP1, or cIAP2 to activate caspases [2, 14]. Notwithstanding the recently reported relationship between IAP antagonists and autophagy, the understanding of the underlying mechanism is still shallow [17]. This study focused on a novel IAP antagonist, WX20120108, and its potent autophagy regulatory activity. The autophagy induction mechanism was systematically unraveled based on the validation that WX20120108 exhibits the 
a

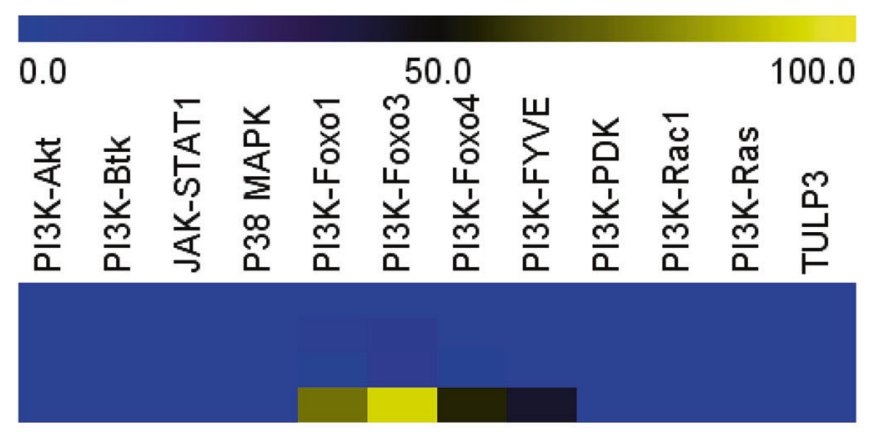

Maximum effect

(\%)

GDC-0152 $30 \mu \mathrm{mol} / \mathrm{L}$ GDC-0152 $100 \mu \mathrm{mol} / \mathrm{L}$ WX20120108 $3 \mu \mathrm{mol} / \mathrm{L}$ WX2012010830 $3 \mathrm{~mol} / \mathrm{L}$

b
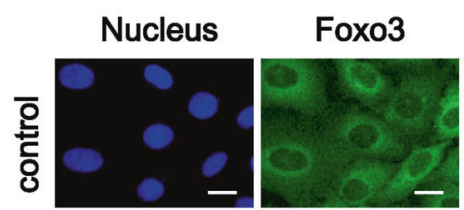

Merge
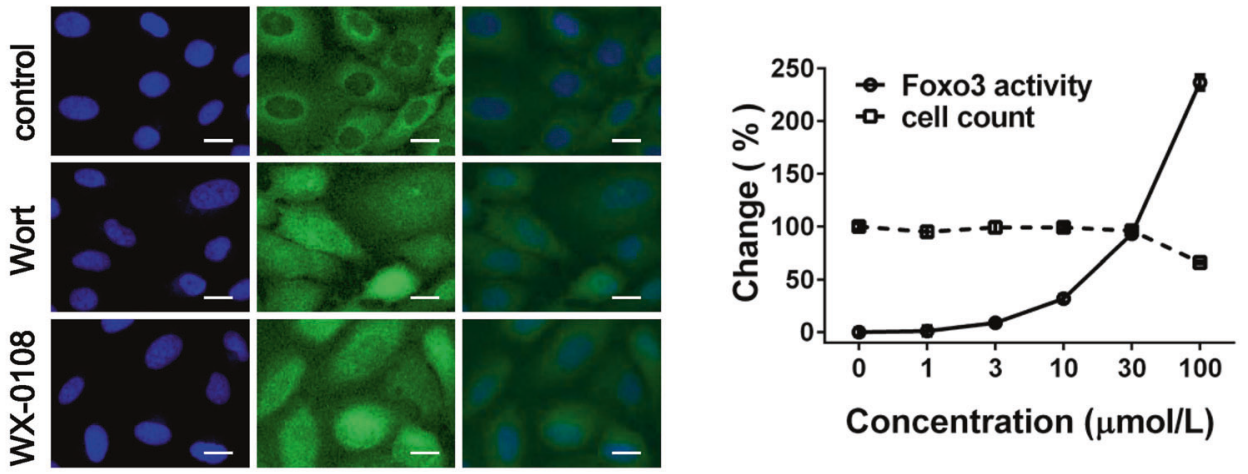

\section{Concentration $(\mu \mathrm{mol} / \mathrm{L})$}

C
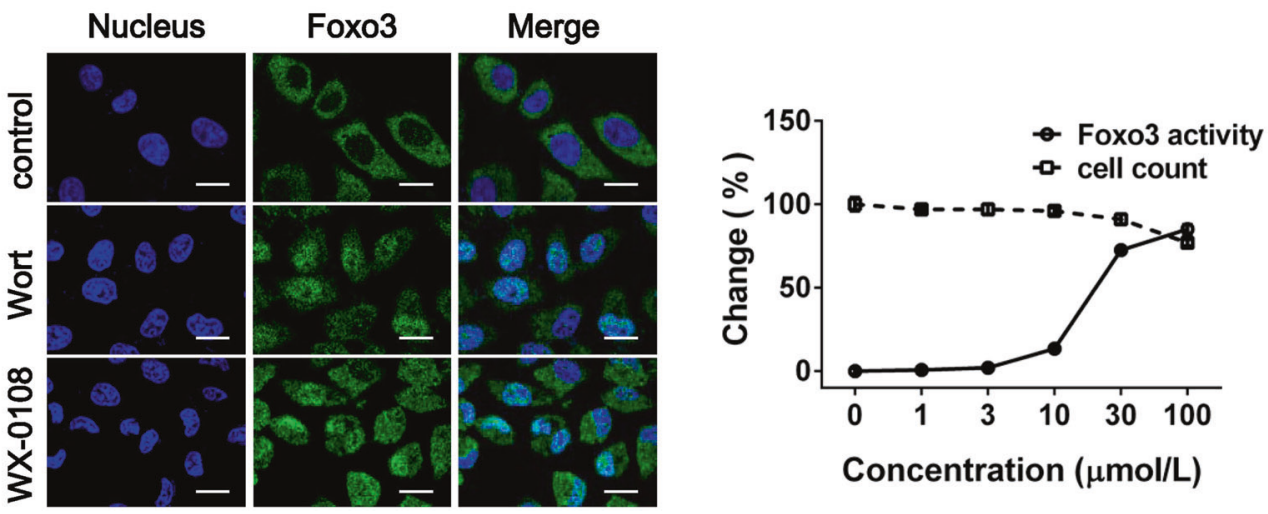

Concentration $(\mu \mathrm{mol} / \mathrm{L})$

Fig. 6 WX20120108 selectively activates Foxo3. a Heat map of the screening results for twelve signaling pathways or targets in EGFP-labeled reporter cell lines. The activity of WX20120108 in pathway assays was expressed as the activity rate relative to the positive control compound $(150,300,150$, and $100 \mathrm{nmol} / \mathrm{L}$ of wortmannin in the PI3K-Foxo1, PI3K-Foxo3, PI3K-Foxo4, and PI3K-FYVE pathways, respectively) and negative control (0.2\% DMSO). b Representative images and concentration response curves of WX20120108 in Foxo3-EGFP_U2OS cells. Scale bar = $10 \mu \mathrm{m}$. c Representative images and concentration response curves of WX20120108 in HeLa cells stained with Hoechst 33342 for nuclei (blue) and primary anti-Foxo3 antibody and Alexa Fluor 488-conjugated secondary antibody for Foxo3 (green). Scale bar $=10 \mu \mathrm{m}$. In (b) and (c), cells were incubated with vehicle $(0.2 \%$ DMSO), wortmannin $(300 \mathrm{nmol} / \mathrm{L})$, and different concentrations of WX20120108 for $1 \mathrm{~h}$ and $12 \mathrm{~h}$, and concentration response curves of activities were calculated relative to the positive ( $300 \mathrm{nmol} / \mathrm{L}$ Wortmannin) and negative control ( $0.2 \%$ DMSO). Values represent the mean $\pm S D, n=3$. Wort Wortmannin, WX-0108: WX20120108

properties of an IAP antagonist and shows more potent antitumor activity than other such compounds.

WX20120108 is a new compound targeting the XIAP-BIR3 structure. Virtual molecular docking showed that WX20120108 strongly interacted with XIAP-BIR3 via several hydrogen bonds at W323, E314, T308, and Q319 residues in the backbone of the BIR3 domain, which shares the same binding sites of Smac-AVPI, the binding peptide of an endogenous IAP antagonist, Smac $[9,52]$. Furthermore, a molecular affinity assay revealed that WX20120108 exhibited high affinity with XIAP, CIAP1, and CIAP2, and the IC 50 values on SM-F2 for the BIR3 domains of XIAP, CIAP1, and CIAP2 reached nanomolar levels. This is consistent with many known IAP antagonists, such as GDC-0152 and SM-406 [11, 32]. Correspondingly, WX20120108 induced rapid degradation of CIAP-1, cleavage of pro-caspase-3 and caspasedependent tumor cell apoptosis in a dose-dependent manner and activated the NF-KB pathway and potentially promoted caspasedependent and TNFa-induced cell death synergistically as revealed by cellular functional assays. These phenomena are unique effects mediated by IAP antagonists through interaction with the target pathway $[14,44,53]$. More interestingly, WX20120108 exhibited much lower $I C_{50}$ values than the known IAP inhibitor GDC-0152 in six different tumor cell lines, including HeLa, HeLa-bcl2, Skov3, Skov3/T, MDA-MB-231, and HepG2, and 
a
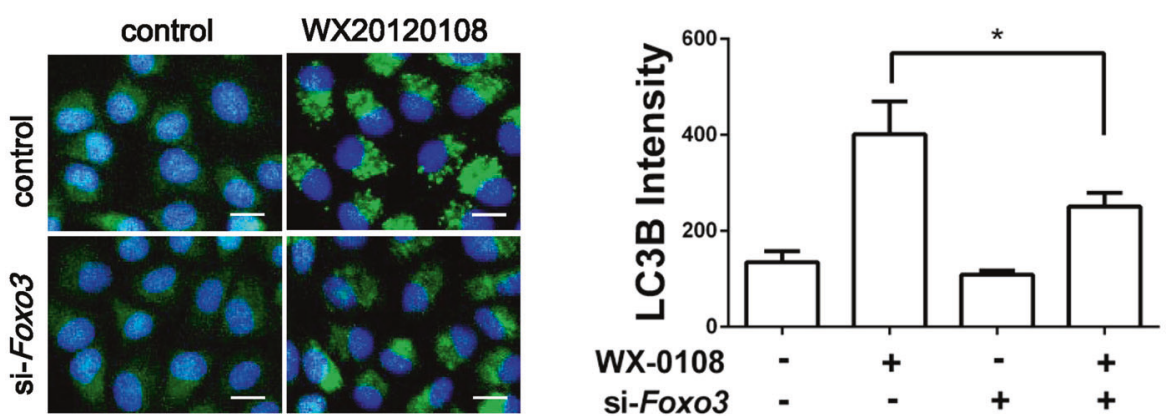

b

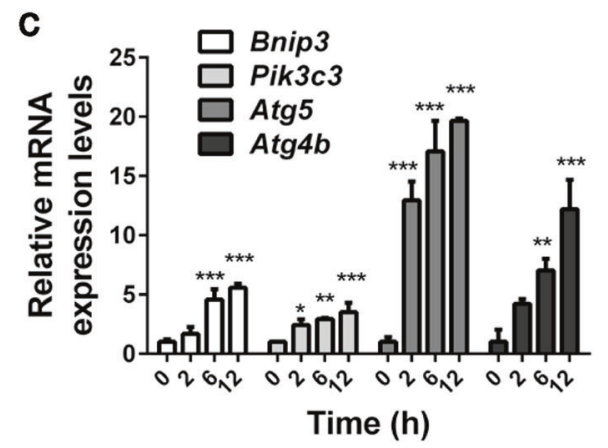

Fig. 7 WX20120108-induced autophagy is mediated by Foxo3 activation in HeLa cells. a, b Foxo3 knockdown significantly decreased WX20120108-induced autophagy as revealed by HCA and Western blotting. Cells were transiently transfected with the Foxo3-specific siRNA for $72 \mathrm{~h}$, followed by treatment with $30 \mu \mathrm{mol} / \mathrm{L}$ WX20120108 for $16 \mathrm{~h}$. Finally, cells were prepared for HCA (scale bar $=10 \mu \mathrm{m}$ ) or Western blotting assay. The fluorescence intensity (FI) of LC3B puncta/cell was analyzed with an IN Cell Analyzer 2000. c Relative Bnip3, Pik3c3, Atg4b, and Atg 5 mRNA levels (compared with $A C T I N$ ) in HeLa cells treated with $30 \mu \mathrm{mol} / \mathrm{L}$ WX20120108 for different periods were analyzed by quantitative RT-PCR. ${ }^{*}$ indicates a significant difference vs. control. ${ }^{*} P<0.05,{ }^{* *} P<0.01,{ }^{* *} P<0.001$

showed less cytotoxicity to normal cells than to cancer cells, just as GDC-0152 does. This evidence clearly indicated that WX2012018 is a novel IAP antagonist with high in vitro anticancer activity.

Autophagic cell death, or type II programmed cell death (PCD), and apoptosis, or type I PCD, can act as partners to induce cell death in a coordinated or cooperative fashion, although they have different processes. Several signaling pathways that are induced by common cellular stressors regulate both autophagy and apoptosis, such as Bcl-2, p53, NF-KB, and Beclin1, among others $[30$, 54]. The potent activity of the novel IAP antagonist WX20120108 on LC3B accumulation in HepG2 cells attracted our attention. In screening experiments, treatment with $30 \mu \mathrm{mol} / \mathrm{L}$ WX2012018 produced even more LC3B puncta than treatment with $100 \mu \mathrm{mol} / \mathrm{L} \mathrm{CQ}$, a well-known autophagy inhibitor, which prevents lysosomal endosomal acidification and blocks fusion of autophagosomes with lysosomes and therefore leads to accumulation of LC3B puncta [55]. This effect has been confirmed in multiple tumor cell types (Supplementary Fig. 1). To systematically investigate the autophagy-regulating characteristics of WX20120108, HeLa, and MDA-MB-231 cells, the main targeting cancers of IAP antagonists, were chosen for this study. Imagingbased HCA, Western blot assay and transmission electron microscopy observation revealed that WX20120108 dose- and time-dependently increased LC3B puncta or LC3B-II formation and formed well-defined autophagosomes in cancer cells, and CQ coincubation significantly enhanced LC3B-II levels after both short-term and long-term WX20120108 exposure. Moreover, colocalization of autophagosomes and lysosomes and lysosomal protease analysis demonstrated that, unlike CQ, WX20120108 promotes the fusion of autophagosomes and lysosomes and significantly increases the activities of CTSB and CTSD, which are the most abundant lysosomal proteases participating directly in the proteolytic degradation of cellular macromolecules in the execution of autophagy [56]. Therefore, apart from being an apoptosis inducer, WX20120108 is also an autophagy inducer, promoting autophagic flux. This was in agreement with the results of previous studies on IAP antagonists, embelin, GDC-0152, and APG-1387, which exhibited autophagy-inducing activity $[15,16,25]$.

Since WX20120108 has been demonstrated to be an autophagy inducer, we first investigated the underlying mechanism with respect to the mammalian target of rapamycin upstream regulatory cascades, including $\mathrm{PI} 3 \mathrm{~K}$ and its associated proteins, such as protein kinase B (PKB)/Akt [57-60], AMPK, and Ras/PKA [58], which are widely accepted as core pathways and targets during autophagy induction. The screening results of the 12 EGFP-tagged reporter cell lines representing PI3K-Akt, PI3K-Btk, JAK-STAT1, p38 MAPK, PI3K-Foxo1, PI3K-Foxo3, PI3K-Foxo4, PI3KFYVE, PI3K-PDK, PI3K-Rac1, PI3K-Ras and TULP3 signaling pathways or targets are interesting. WX20120108 dose-dependently activated PI3K-Foxo3 and activated PI3K-Foxo1, PI3K-Foxo4 and PI3K-FYVE only at high concentration $(30 \mu \mathrm{mol} / \mathrm{L})$ but did not affect any other PI3K-related proteins or pathways. Thus, FOXOs activation seems to be a selective action of WX20120108. Foxo3 is a member of the FOXO subfamily of transcription factors [61]. When Foxo3 is activated, it is translocated into the nucleus, where it upregulates the expression of Bnip3, Pik3c3, BECN1, Ulk2, Atg4B, and $A t g 5$, genes that are involved in autophagic pathway induction and autophagosome formation [50, 62]. Foxo3 activation-regulated autophagy has previously been described in various cell types [63]. Here, WX20120108-induced Foxo3 activation and its relationship with autophagy were further validated and explored in HeLa cells. Consistent with the results of the EGFP-reporter cell lines, WX20120108 dose-dependently activated Foxo3 in HeLa cells and upregulated the expression of 
a

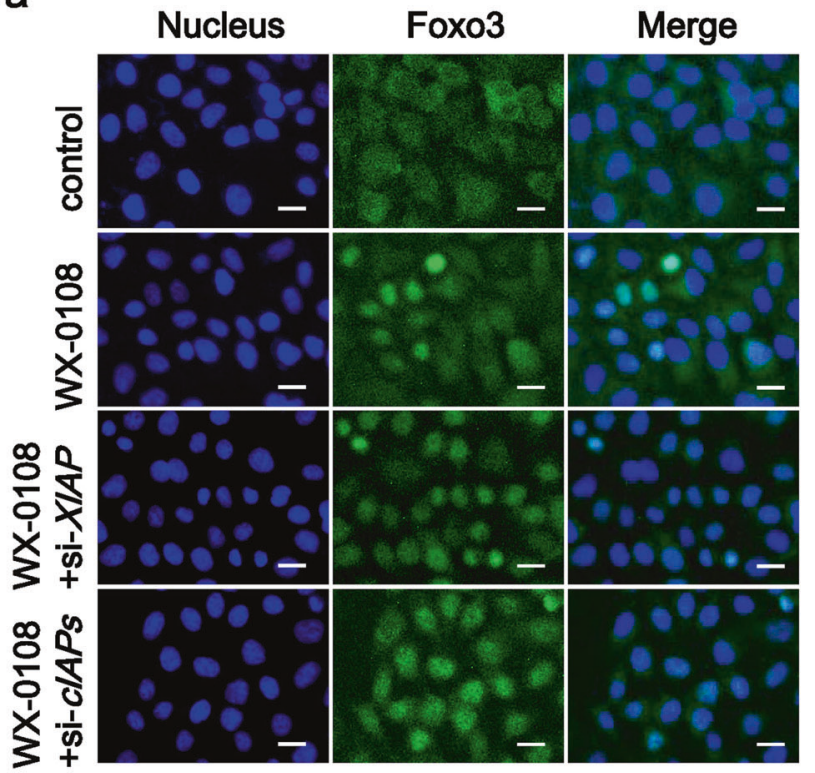

d

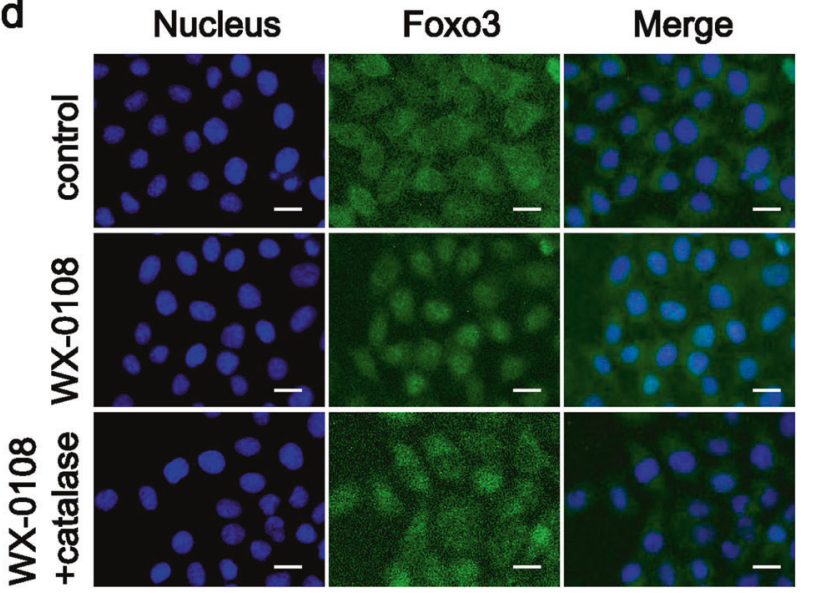

b

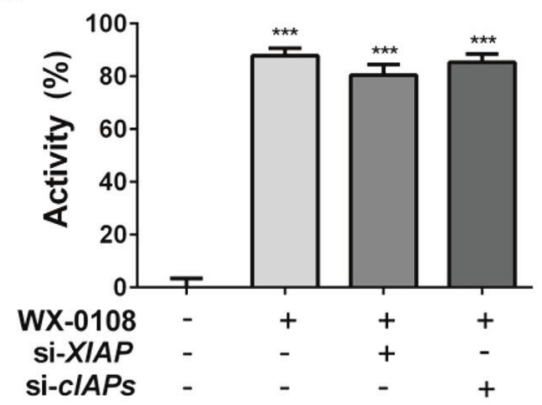

C

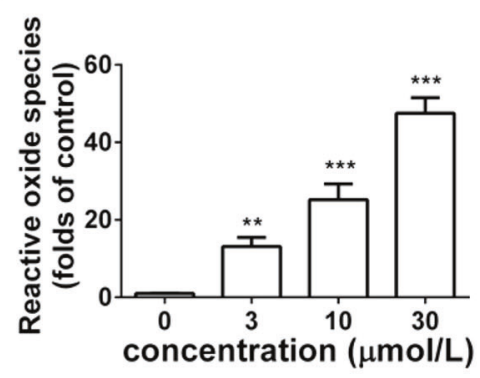

e

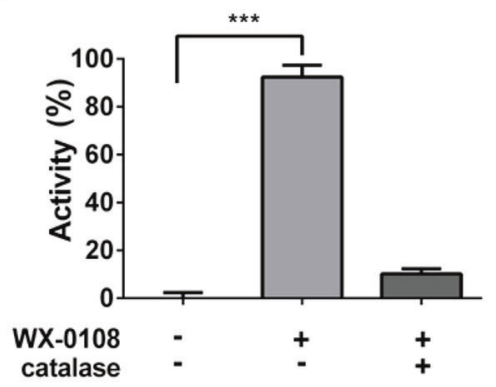

g

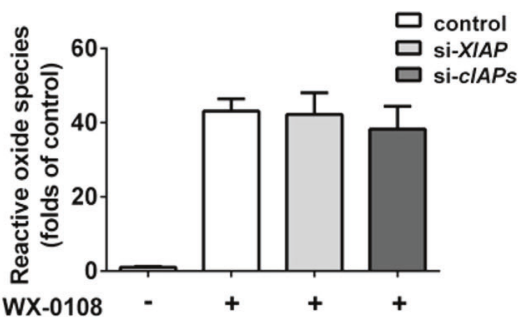

Fig. 8 WX20120108 induced-Foxo3 activation depends on ROS released in HeLa cells. a Representative images and quantitative results b of HeLa cells transfected with siRNA against XIAP or CIAP1 and CIAP2, as indicated, followed by treatment with $30 \mu \mathrm{mol} / \mathrm{L}$ WX20120108 for $12 \mathrm{~h}$. Foxo3 nuclear translocation (activation) was assayed by HCA using an IN Cell Analyzer 2000. Scale bar $=10 \mu \mathrm{m}$. c WX20120108 dosedependently increased intracellular ROS levels after treatment for $6 \mathrm{~h}$ as measured using the green fluorescent dye CM- $\mathrm{H}_{2} \mathrm{DCFDA}$. d Representative images and quantitative results e of $500 \mathrm{U} / \mathrm{mL}$ catalase (a known ROS scavenger) on $30 \mu \mathrm{mol} / \mathrm{L}$ WX20120108-induced Foxo3 nuclear translocation (activation) as assayed by HCA. Scale bar $=10 \mu \mathrm{m}$. $\mathbf{f}$ The effect of $30 \mu \mathrm{mol} / \mathrm{L}$ WX20120108 on LC3B-II in the presence of catalase, the ROS scavenger. g ROS produced by treatment with $30 \mu \mathrm{mol} / \mathrm{L}$ WX20120108 for $6 \mathrm{~h}$ was not affected by transfection of siRNA against XIAP or CIAP1 and CIAP2. ${ }^{* *} P<0.01,{ }^{* * *} P<0.001$

Foxo3-target genes after treatment for $2 \mathrm{~h}$. Silencing of Foxo3 significantly suppressed LC3B-II formation produced by WX20120108. Therefore, WX20120108-induced Foxo3 activation is an important mediator of sustained autophagy induced by WX20120108.
As a transcription factor, FOXOs can be regulated by some regulatory factors, including Akt [64], p38 pathway [65], as well as oxidative stress [49], especially ROS. ROS could modulate the activities of FOXOs at multiple levels, including posttranslational modifications of FOXOs (such as phosphorylation and acetylation), 
interaction with coregulators, alterations in the subcellular localization of FOXOs, and protein synthesis and stability $[49,66]$. Considering that WX20120108 did not affect the Akt and p38 pathways, we investigated cellular ROS levels. It is interesting that WX20120108 dose-dependently promoted ROS release after $6 \mathrm{~h}$ of incubation, and catalase (a known ROS scavenger) suppressed Foxo3 activation and LC3B-II formation induced by WX20120108. These results indicated that ROSmediated Foxo3 activation is involved in the WX20120108induced autophagy.

Although some studies have explored the relationship between IAPs (including XIAP and CIAP1/2) or their antagonists and autophagy, the exact role of XIAP or CIAP1/2 in autophagy is still controversial. Huang et al. [26] reported that XIAP inhibited autophagy via the XIAP-Mdm2-p53 pathway, whereas Lin et al. [27] found that XIAP and CIAP1/2 induced autophagy via NF-KB activation. Whether IAP antagonist-induced autophagy depends on XIAP and CIAP1/2 has not yet been reported. In this study, knockdown of XIAP or CIAP1/2 affected neither the release of ROS nor Foxo3 activation induced by WX20120108. Transfection with siRNA against CIAP1/2 and not against XIAP partially impaired WX20120108-induced autophagy (Supplementary Fig. 2), which is similar to GDC-0152 (unpublished). This indicated that apart from the CIAP1/2-dependent pathway, the XIAP and CIAP1/2-independent ROS-Foxo3 pathway plays an important role in WX20120108induced autophagy. In addition, we have observed in the unbiased screening of autophagy-related signaling pathways that GDC-0152 also exhibited similar selectivity on PI3K-Foxo1, Foxo3, Foxo4, and FYVE; however, the effect is very weak, which might be the reason that WX20120108 exhibits stronger autophagy activity.

p62 has been proposed to regulate the packaging and delivery of polyubiquitinated, misfolded, and aggregated proteins and dysfunctional organelles for their degradation via autophagy in mammalian cells [67]. Therefore, p62 level is used as an indicator for identifying autophagy inducers and blockers. Autophagy inducers decrease the p62 level, while autophagy blockers or inhibitors increase the p62 level [46]. In this study, the p62 level increased after WX20120108 treatment in a time- and dosedependent manner in cancer cells, which seemed to be in contrast to the general opinion. Recently, however, a p62-independent autophagic pathway has been proposed [57], and p62upregulation has been reported in some studies while autophagic flux increased [68-70]. In addition, p62 is a multifunctional factor involved in several cellular pathways. The p62 level is regulated not only by autophagic degradation but also by autophagyindependent transcriptional regulation [71-75]. For example, the transcription of p62 is modulated by oxidative stress (Nrf2), the Ras/MAPK pathway, and the JNK/C-Jun pathway [76]. Based on these findings, we further assessed p62 mRNA levels after WX20120108 treatment. The results indicated that WX20120108 treatment increased $p 62$ mRNA levels in both HeLa and MDA-MB231 cells in a time-dependent manner, which might explain why the p62 level increased instead of decreasing after WX20120108 treatment. This finding is consistent with the WX20120108mediated regulation of oxidative stress.

Promotion of apoptosis has been speculated to be the major way by which IAP antagonists cause cancer cell death [14]. In this study, WX20120108 exhibited the profiles of IAP antagonists by inducing caspase-dependent apoptosis, which accounts for approximately $80 \%-90 \%$ of total cell death in both HeLa and MDA-MB-231 cells after treatment with 30-100 $\mu \mathrm{mol} / \mathrm{L}$ WX20120108. On the other hand, the parallel dynamic observations on cellular autophagy and cell survival showed that as the concentration of WX20120108 increased or the incubation time prolonged, the cellular LC3B level increased, and there was an evident "switch" from autophagy to cell death, and this autophagy is not affected by Z-VAD-FMK, a pan-caspase inhibitor. These results indicated that WX20120108-induced cell death embraced apoptosis and autophagy, and autophagy took place earlier than apoptosis. A similar phenomenon was reported by You-Jin Lee et al. They found that the XIAP inhibitor embelin induces autophagic and apoptotic cell death in human oral squamous cell carcinoma cells [15]. However, the mechanism by which IAP antagonist or WX20120108 switches autophagy to apoptosis remains to be studied.

In summary, based on the characterizations of the novel IAP antagonist WX2012018, this study revealed, for the first time, that the IAP-independent ROS-Foxo3 pathway is involved in the tumor cell autophagy induced by WX20120108. This finding provides important insight into the molecular regulatory mechanism of autophagy induced by an IAP antagonist and provides more information for the development of a novel IAP antagonist.

\section{ACKNOWLEDGEMENTS}

We would like to thank Professor Shaomeng Wang at the University of Michigan in the U.S. for his assistance in the FPA competition assay. This work was supported by the National Natural Science Foundation of China (Grant nos. 81803567 and 81773790) and the National Science and Technology Major Project of the Ministry of Science and Technology of China (Grant nos. 2012ZX09301-001 and 2012ZX09301-003) and partially supported by a project of the State Key Laboratory of Functions and Applications of Medicinal Plants, Guizhou Medical University (FAMP201708K).

\section{AUTHOR CONTRIBUTIONS}

$\mathrm{RD}, \mathrm{AHN}$ and LLW designed the research; RD, XW, WC, ZL, ALW and QBW performed the research; RD and LLW wrote the paper; XW and $A H N$ provided the testing compound; LLW, WC, ZL and AHN reviewed and modified the paper.

\section{ADDITIONAL INFORMATION}

The online version of this article (https://doi.org/10.1038/s41401-019-0253-5) contains supplementary material, which is available to authorized users.

Competing interests: The authors declare no competing interests.

\section{REFERENCES}

1. Hanahan D, Weinberg RA. The hallmarks of cancer. Cell. 2000;100:57-70.

2. Hunter AM, LaCasse EC, Korneluk RG. The inhibitors of apoptosis (IAPs) as cancer targets. Apoptosis. 2007;12:1543-68.

3. Tamm I, Kornblau SM, Segall H, Krajewski S, Welsh K, Kitada S, et al. Expression and prognostic significance of IAP-family genes in human cancers and myeloid leukemias. Clin Cancer Res. 2000;6:1796-803.

4. Sun C, Cai M, Gunasekera AH, Meadows RP, Wang H, Chen J, et al. NMR structure and mutagenesis of the inhibitor-of-apoptosis protein XIAP. Nature. 1999;401:818-22.

5. Chai J, Shiozaki E, Srinivasula SM, Wu Q, Datta $P$, Alnemri ES, et al. Structural basis of caspase-7 inhibition by XIAP. Cell. 2001;104:769-80.

6. Riedl SJ, Renatus M, Schwarzenbacher R, Zhou Q, Sun C, Fesik SW, et al. Structural basis for the inhibition of caspase-3 by XIAP. Cell. 2001;104:791-800.

7. Wang CY, Mayo MW, Korneluk RG, Goeddel DV, Baldwin AS Jr. NF-kappaB antiapoptosis: induction of TRAF1 and TRAF2 and C-IAP1 and C-IAP2 to suppress caspase-8 activation. Science. 1998;281:1680-3.

8. de Almagro MC, Vucic D. The inhibitor of apoptosis (IAP) proteins are critical regulators of signaling pathways and targets for anti-cancer therapy. Exp Oncol. 2012:34:200-11.

9. Fulda S. Smac mimetics as IAP antagonists. Semin Cell Dev Biol. 2015;39:132-8.

10. Brunckhorst MK, Lerner D, Wang S, Yu Q. AT-406, an orally active antagonist of multiple inhibitor of apoptosis proteins, inhibits progression of human ovarian cancer. Cancer Biol Ther. 2012;13:804-11.

11. Flygare JA, Beresini M, Budha N, Chan H, Chan IT, Cheeti S, et al. Discovery of a potent small-molecule antagonist of inhibitor of apoptosis (IAP) proteins and clinical candidate for the treatment of cancer (GDC-0152). J Med Chem. 2012;55:4101-13.

12. Srinivasula $S M$, Hegde $R$, Saleh A, Datta $P$, Shiozaki E, Chai J, et al. A conserved XIAP-interaction motif in caspase- 9 and Smac/DIABLO regulates caspase activity and apoptosis. Nature. 2001;410:112-6. 
13. Vince JE, Wong WW, Khan N, Feltham R, Chau D, Ahmed AU, et al. IAP antagonists target CIAP1 to induce TNFalpha-dependent apoptosis. Cell. 2007;131:682-93.

14. Gyrd-Hansen M, Meier P. IAPs: from caspase inhibitors to modulators of NFkappaB, inflammation and cancer. Nat Rev Cancer. 2010;10:561-74.

15. Lee YJ, Park BS, Park HR, Yu SB, Kang HM, Kim IR. XIAP inhibitor embelin induces autophagic and apoptotic cell death in human oral squamous cell carcinoma cells. Environ Toxicol. 2017;32:2371-8.

16. Li BX, Wang HB, Qiu MZ, Luo QY, Yi HJ, Yan XL, et al. Novel smac mimetic APG1387 elicits ovarian cancer cell killing through TNF-alpha, Ripoptosome and autophagy mediated cell death pathway. J Exp Clin Cancer Res. 2018;37:53.

17. Wang YF, Zhang W, He KF, Liu B, Zhang L, Zhang WF, et al. Induction of autophagy-dependent cell death by the survivin suppressant YM155 in salivary adenoid cystic carcinoma. Apoptosis. 2014;19:748-58.

18. Wang Q, Chen Z, Diao X, Huang S. Induction of autophagy-dependent apoptosis by the survivin suppressant YM155 in prostate cancer cells. Cancer Lett. 2011;302:29-36

19. Ding YH, Fan XD, Wu JJ, Deng ZK, Wei B, Li YF. Effect of YM155 on apoptosis and autophagy of K562 Cells. Zhongguo Shi Yan Xue Ye Xue Za Zhi. 2015;23:375-80.

20. Zhang L, Zhang W, Wang YF, Liu B, Zhang WF, Zhao YF, et al. Dual induction of apoptotic and autophagic cell death by targeting survivin in head neck squamous cell carcinoma. Cell Death Dis. 2015;6:e1771.

21. Cheng SM, Chang YC, Liu CY, Lee JY, Chan HH, Kuo CW, et al. YM155 downregulates survivin and XIAP, modulates autophagy and induces autophagydependent DNA damage in breast cancer cells. Br J Pharmacol. 2015;172:214-34.

22. Vequaud $E$, Seveno $C$, Loussouarn D, Engelhart $L$, Campone $M$, Juin $P$, et al. YM155 potently triggers cell death in breast cancer cells through an autophagyNF-KB network. Oncotarget. 2015;6:13476-86.

23. Pennati $M$, Sbarra S, De Cesare M, Lopergolo A, Locatelli SL, Campi $E$, et al. YM155 sensitizes triple-negative breast cancer to membrane-bound TRAIL through p38 MAPK- and CHOP-mediated DR5 upregulation. Int J Cancer. 2015;136:299-309.

24. Jane EP, Premkumar DR, Sutera PA, Cavaleri JM, Pollack IF. Survivin inhibitor YM155 induces mitochondrial dysfunction, autophagy, DNA damage and apoptosis in Bcl-xL silenced glioma cell lines. Mol Carcinog. 2017;56:1251-65.

25. Peiqi $L$, Rong $H$, Hongming $D$, Zhuogang L, Wei J, Miao M. GDC-0152-induced autophagy promotes apoptosis in HL-60 cells. Mol Cell Biochem. 2018;445:135-43.

26. Huang X, Wu Z, Mei Y, Wu M. XIAP inhibits autophagy via XIAP-Mdm2-p53 signalling. EMBO J. 2013;32:2204-16.

27. Lin F, Ghislat G, Luo S, Renna M, Siddiqi F, Rubinsztein DC. XIAP and CIAP1 amplifications induce Beclin 1-dependent autophagy through NFkappaB activation. Hum Mol Genet. 2015;24:2899-913.

28. Levine B, Klionsky DJ. Development by self-digestion: molecular mechanisms and biological functions of autophagy. Dev Cell. 2004;6:463-77.

29. Gozuacik D, Kimchi A. Autophagy as a cell death and tumor suppressor mechanism. Oncogene. 2004;23:2891-906.

30. Gump JM, Thorburn A. Autophagy and apoptosis- what's the connection? Trends Cell Biol. 2011;21:387-92.

31. Eisenberg-Lerner A, Bialik S, Simon HU, Kimchi A. Life and death partners: apoptosis, autophagy and the cross-talk between them. Cell Death Differ. 2009;16:966-75.

32. Cai Q, Sun H, Peng Y, Lu J, Nikolovska-Coleska Z, McEachern D, et al. A potent and orally active antagonist (SM-406/AT-406) of multiple inhibitor of apoptosis proteins (IAPs) in clinical development for cancer treatment. J Med Chem. 2011;54:2714-26.

33. Wang S. Design of small-molecule Smac mimetics as IAP antagonists. Curr Top Microbiol Immunol. 2011;348:89-113.

34. Nikolovska-Coleska $Z$, Wang $R$, Fang $X$, Pan $H$, Tomita $Y, L i ~ P$, et al. Development and optimization of a binding assay for the XIAP BIR3 domain using fluorescence polarization. Anal Biochem. 2004;332:261-73.

35. Skehan P, Storeng R, Scudiero D, Monks A, McMahon J, Vistica D, et al. New colorimetric cytotoxicity assay for anticancer-drug screening. J Natl Cancer Inst. 1990;82:1107-12.

36. Vichai V, Kirtikara K. Sulforhodamine B colorimetric assay for cytotoxicity screening. Nat Protoc. 2006;1:1112-6.

37. Xiao D, Vogel V, Singh SV. Benzyl isothiocyanate-induced apoptosis in human breast cancer cells is initiated by reactive oxygen species and regulated by Bax and Bak. Mol Cancer Ther. 2006;5:2931-45.

38. Li F, Wei A, Bu L, Long L, Chen W, Wang C, et al. Procaspase-3-activating compound 1 stabilizes hypoxia-inducible factor 1alpha and induces DNA damage by sequestering ferrous iron. Cell Death Dis. 2018;9:1025.

39. Shao Y, Gao Z, Marks PA, Jiang X. Apoptotic and autophagic cell death induced by histone deacetylase inhibitors. Proc Natl Acad Sci USA. 2004;101:18030-5

40. Chen W, Fan S, Xie X, Xue N, Jin X, Wang L. Novel PPAR pan agonist, ZBH ameliorates hyperlipidemia and insulin resistance in high fat diet induced hyperlipidemic hamster. PLoS One. 2014;9:e96056.
41. Wu G, Chai J, Suber TL, Wu JW, Du C, Wang X, et al. Structural basis of IAP recognition by Smac/DIABLO. Nature. 2000;408:1008-12.

42. Zhang Y, Zhu J, Tang Y, Li F, Zhou H, Peng B, et al. X-linked inhibitor of apoptosis positive nuclear labeling: a new independent prognostic biomarker of breast invasive ductal carcinoma. Diagn Pathol. 2011;6:49.

43. Liu SS, Tsang BK, Cheung AN, Xue WC, Cheng DK, Ng TY, et al. Anti-apoptotic proteins, apoptotic and proliferative parameters and their prognostic significance in cervical carcinoma. Eur J Cancer. 2001;37:1104-10.

44. Li L, Thomas RM, Suzuki H, De Brabander JK, Wang X, Harran PG. A small molecule Smac mimic potentiates TRAIL- and TNFalpha-mediated cell death. Science. 2004:305:1471-4.

45. Klionsky DJ. Guidelines for the use and interpretation of assays for monitoring autophagy in higher eukaryotes. Autophagy. 2008;25:151-75.

46. Klionsky DJ, Abdelmohsen K, Abe A, Abedin MJ, Abeliovich H, Acevedo Arozena $A$, et al. Guidelines for the use and interpretation of assays for monitoring autophagy (3rd edition). Autophagy. 2016;12:1-222.

47. Mizushima N, Yoshimori T, Levine B. Methods in mammalian autophagy research. Cell. 2010;140:313-26.

48. McGovern SL, Caselli E, Grigorieff N, Shoichet BK. A common mechanism underlying promiscuous inhibitors from virtual and high-throughput screening. J Med Chem. 2002;45:1712-22.

49. Webb $A E$, Brunet $A$. FOXO transcription factors: key regulators of cellular quality control. Trends Biochem Sci. 2014;39:159-69.

50. Zhao J, Brault JJ, Schild A, Cao P, Sandri M, Schiaffino S, et al. FoxO3 coordinately activates protein degradation by the autophagic/lysosomal and proteasomal pathways in atrophying muscle cells. Cell Metab. 2007;6:472-83.

51. Ameziane El Hassani R, Dupuy C. Detection of intracellular reactive oxygen species (CM-H2DCFDA). Bio-Protocol. 2013;3:e313.

52. Liu Z, Sun C, Olejniczak ET, Meadows RP, Betz SF, Oost T, et al. Structural basis for binding of Smac/DIABLO to the XIAP BIR3 domain. Nature. 2000; 408:1004-8.

53. Finlay D, Vamos M, Gonzalez-Lopez M, Ardecky RJ, Ganji SR, Yuan H, et al. Smallmolecule IAP antagonists sensitize cancer cells to TRAIL-induced apoptosis: roles of XIAP and cIAPs. Mol Cancer Ther. 2014;13:5-15.

54. Thorburn A. Apoptosis and autophagy: regulatory connections between two supposedly different processes. Apoptosis. 2008;13:1-9.

55. Steinman RM, Mellman IS, Muller WA, Cohn ZA. Endocytosis and the recycling of plasma membrane. J Cell Biol. 1983;96:1-27.

56. Turk B, Stoka V, Rozman-Pungercar J, Cirman T, Droga-Mazovec G, Oresic K, et al. Apoptotic pathways: involvement of lysosomal proteases. Biol Chem. 2002;383:1035-44.

57. Galluzzi L, Baehrecke EH, Ballabio A, Boya P, Bravo-San Pedro JM, Cecconi F, et al. Molecular definitions of autophagy and related processes. EMBO J. 2017;36:1811-36.

58. Noda NN, Inagaki F. Mechanisms of autophagy. Annu Rev Biophys. 2015:44:101-22.

59. He C, Klionsky DJ. Regulation mechanisms and signaling pathways of autophagy. Annu Rev Genet. 2009;43:67-93.

60. Yang Z, Klionsky DJ. Mammalian autophagy: core molecular machinery and signaling regulation. Curr Opin Cell Biol. 2010;22:124-31.

61. Sengupta A, Molkentin JD, Yutzey KE. FoxO transcription factors promote autophagy in cardiomyocytes. J Biol Chem. 2009;284:28319-31.

62. Yang J, Carra S, Zhu WG, Kampinga HH. The regulation of the autophagic network and its implications for human disease. Int J Biol Sci. 2013;9:1121-33.

63. Lv P, Huang J, Yang J, Deng Y, Xu J, Zhang X, et al. Autophagy in muscle of glucose-infusion hyperglycemia rats and streptozotocin-induced hyperglycemia rats via selective activation of $\mathrm{m}$-TOR or FoxO3. PLoS One. 2014;9: e87254.

64. Hay N. Interplay between FOXO, TOR, and Akt. Biochim Biophys Acta. 2011;1813:1965-70.

65. Ho KK, McGuire VA, Koo CY, Muir KW, de Olano N, Maifoshie E, et al. Phosphorylation of FOXO3a on Ser-7 by p38 promotes its nuclear localization in response to doxorubicin. J Biol Chem. 2012;287:1545-55.

66. Klotz LO, Sanchez-Ramos C, Prieto-Arroyo I, Urbanek P, Steinbrenner H, Monsalve M. Redox regulation of FoxO transcription factors. Redox Biol. 2015;6:51-72.

67. Moscat J, Diaz-Meco MT. p62 at the crossroads of autophagy, apoptosis, and cancer. Cell. 2009;137:1001-4.

68. Toepfer N, Childress C, Parikh A, Rukstalis D, Yang W. Atorvastatin induces autophagy in prostate cancer PC3 cells through activation of LC3 transcription. Cancer Biol Ther. 2011;12:691-9.

69. Colosetti P, Puissant A, Robert G, Luciano F, Jacquel A, Gounon P, et al. Autophagy is an important event for megakaryocytic differentiation of the chronic myelogenous leukemia K562 cell line. Autophagy. 2009;5:1092-8.

70. Zheng Q, Su H, Ranek MJ, Wang X. Autophagy and p62 in cardiac proteinopathy. Circ Res. 2011;109:296-308. 
71. Fujita K, Maeda D, Xiao Q, Srinivasula SM. Nrf2-mediated induction of p62 controls Toll-like receptor-4-driven aggresome-like induced structure formation and autophagic degradation. Proc Natl Acad Sci USA. 2011;108: 1427-32.

72. Nakaso K, Yoshimoto Y, Nakano T, Takeshima T, Fukuhara $Y$, Yasui K, et al. Transcriptional activation of p62/A170/ZIP during the formation of the aggregates: possible mechanisms and the role in Lewy body formation in Parkinson's disease. Brain Res. 2004;1012:42-51.

73. Trocoli A, Bensadoun P, Richard E, Labrunie G, Merhi F, Schlafli AM, et al. p62/ SQSTM1 upregulation constitutes a survival mechanism that occurs during granulocytic differentiation of acute myeloid leukemia cells. Cell Death Differ. 2014;21:1852-61.

74. B'Chir W, Maurin AC, Carraro V, Averous J, Jousse C, Muranishi Y, et al. The elF2alpha/ATF4 pathway is essential for stress-induced autophagy gene expression. Nucleic Acids Res. 2013;41:7683-99.

75. Cnop M, Abdulkarim B, Bottu G, Cunha DA, Igoillo-Esteve M, Masini M, et al. RNA sequencing identifies dysregulation of the human pancreatic islet transcriptome by the saturated fatty acid palmitate. Diabetes. 2014;63:1978-93.

76. Puissant A, Fenouille N, Auberger P. When autophagy meets cancer through p62/ SQSTM1. Am J Cancer Res. 2012;2:397-413. 